\title{
FINAL
}

CONTRACT REPORT

VTRC 08-CR11

\section{PORTABLE IMAGE ANALYSIS SYSTEM FOR CHARACTERIZING AGGREGATE MORPHOLOGY}

\author{
LINBING WANG, Ph.D., P.E. \\ Center for Sustainable Transportation Infrastructure \\ Virginia Tech Transportation Institute \\ D. STEPHEN LANE \\ Associate Principal Research Scientist \\ Virginia Transportation Research Council \\ YANG LU \\ Graduate Student \\ Department of Civil and Environmental Engineering \\ Virginia Tech
}

\section{CRISTIAN DRUTA, Ph.D.}

Research Associate

Center for Sustainable Transportation Infrastructure

Virginia Tech Transportation Institute 
Standard Title Page - Report on Federally Funded Project

\begin{tabular}{|c|c|c|}
\hline $\begin{array}{l}\text { 1. Report No. } \\
\text { FHWA/VTRC 08-CR11 }\end{array}$ & 2. Government Accession No. & 3. Recipient's Catalog No. \\
\hline \multirow{2}{*}{\multicolumn{2}{|c|}{$\begin{array}{l}\text { 4. Title and Subtitle } \\
\text { Portable Image Analysis System for Characterizing Aggregate Morphology }\end{array}$}} & $\begin{array}{l}\text { 5. Report Date } \\
\text { February } 2008 \\
\end{array}$ \\
\hline & & 6. Performing Organization Code \\
\hline \multicolumn{2}{|c|}{$\begin{array}{l}\text { 7. Author(s) } \\
\text { Linbing Wang, D. Stephen Lane, Yang Lu, and Cristian Druta }\end{array}$} & $\begin{array}{l}\text { 8. Performing Organization Report No. } \\
\text { VTRC 08-CR11 }\end{array}$ \\
\hline \multirow{2}{*}{\multicolumn{2}{|c|}{$\begin{array}{l}\text { 9. Performing Organization and Address } \\
\text { Virginia Transportation Research Council } \\
530 \text { Edgemont Road } \\
\text { Charlottesville, VA } 22903\end{array}$}} & 10. Work Unit No. (TRAIS) \\
\hline & & $\begin{array}{l}\text { 11. Contract or Grant No. } \\
82561\end{array}$ \\
\hline \multirow{2}{*}{$\begin{array}{l}\text { 12. Sponsoring Agencies' Name and Address } \\
\text { Virginia Department of Transportation } \\
1401 \text { E. Broad Street } \\
\text { Richmond, VA } 23219\end{array}$} & \multirow{2}{*}{$\begin{array}{l}\text { Federal Highway Administration } \\
400 \text { North 8th Street, Room } 750 \\
\text { Richmond, VA 23219-4825 }\end{array}$} & $\begin{array}{l}\text { 13. Type of Report and Period Covered } \\
\text { Final Contract }\end{array}$ \\
\hline & & 14. Sponsoring Agency Code \\
\hline
\end{tabular}

15. Supplementary Notes

\section{Abstract}

In the last decade, the application of image-based evaluation of particle shape, angularity and texture has been widely researched to characterize aggregate morphology. These efforts have been driven by the knowledge that the morphologic characteristics affect the properties and ultimate performance of aggregate mixtures in hot-mixed asphalt, hydraulic cement concrete and bound and unbound pavement layers, yet the lack of rapid, objective, and quantitative methods for assessment have inhibited their application in the engineering process. Developed systems for computer-based imaging and image analysis can cost up to \$3040,000 and are usually not portable to the field. However, recent advances in technology have produced pocket computers having as much processing power as was available in some desktop computers. This project takes advantage of these advances to develop an inexpensive portable image analysis system for characterizing aggregate morphology. The system was developed with an integral pocket computer-high resolution camera but can also use individual components consisting of a digital camera and lap- or desk-top computer.

Digital images of aggregate particles are captured with the camera. These images are analyzed within the Matlab software program environment with a macro developed and written for this project that uses Fast Fourier Transform to characterize the particle morphology with respect to three parameters: shape, angularity and texture, based on the particle perimeter (outline or edge). By analyzing a number of particles from a source, it can be characterized with respect to these three parameters.

Following development of the analysis program, 10 coarse aggregates from various Virginia sources were analyzed. Particles of each aggregate were randomly chosen so that each group contained the various shapes and textures representative of the source. Three images of each particle were obtained at distances of 2, 3, and 10 in to evaluate the resolution needed for adequate analysis. The reliability of the image processing was assessed by statistically analyzing the shape, angularity, and texture values to determine how the threshold parameter affects the particle edge acquisition. Asymptotic analysis was performed to determine the number of images needed to obtain a statistically stable value for each aggregate parameter.

It was determined that images acquired at close range ( 2 or 3 in) were needed to provide sufficient resolution to adequately characterize the aggregate. It was also found that statistically valid values for aggregate shape, angularity, and texture can be obtained from fifteen particle images of random orientation. It can be concluded that the system can be successfully used to characterize coarse aggregate morphology.

It is recommended that the Virginia Department of Transportation's Materials Division begin collecting images of aggregates used statewide and collaborate with the VTRC to perform the characterizations and build the database of aggregate morphologic characteristics. This information, coupled with performance testing of the materials, will provide the basis for incorporating the characterization parameters into specifications and guide material usage in the future.

\begin{tabular}{|l|l|}
\hline $\begin{array}{l}17 \text { Key Words } \\
\text { Aggregate, shape, angularity, texture, morphology, image analysis }\end{array}$ & $\begin{array}{l}\text { 18. Distribution Statement } \\
\text { No restrictions. This document is available to the public through NTIS, } \\
\text { Springfield, VA 22161. }\end{array}$
\end{tabular}

\begin{tabular}{|l|l|l|l}
\hline $\begin{array}{l}\text { 19. Security Classif. (of this report) } \\
\text { Unclassified }\end{array}$ & $\begin{array}{l}\text { 20. Security Classif. (of this page) } \\
\text { Unclassified }\end{array}$ & $\begin{array}{l}\text { 21. No. of Pages } \\
58\end{array}$ & 22. Price \\
\hline
\end{tabular}

Form DOT F 1700.7 (8-72) Reproduction of completed page authorized 
FINAL CONTRACT REPORT

PORTABLE IMAGE ANALYSIS SYSTEM FOR CHARACTERIZING AGGREGATE MORPHOLOGY

Linbing Wang, Ph.D., P.E.

Associate Director

Center for Sustainable Transportation Infrastructure

Virginia Tech Transportation Institute

D. Stephen Lane

Associate Principal Research Scientist

Virginia Transportation Research Council

\author{
Yang Lu \\ Graduate Student \\ Department of Civil and Environmental Engineering \\ Virginia Tech \\ Cristian Druta, Ph.D. \\ Research Associate \\ Center for Sustainable Transportation Infrastructure \\ Virginia Tech Transportation Institute
}

Project Manager

D. Stephen Lane, Virginia Transportation Research Council

Contract Research Sponsored by the

Virginia Transportation Research Council

In Cooperation with the U.S. Department of Transportation

Federal Highway Administration

Virginia Transportation Research Council

(A partnership of the Virginia Department of Transportation

and the University of Virginia since 1948)

Charlottesville, Virginia

February 2008

VTRC 08-CR11 


\section{NOTICE}

The project that is the subject of this report was done under contract for the Virginia Department of Transportation, Virginia Transportation Research Council. The contents of this report reflect the views of the authors, who are responsible for the facts and the accuracy of the data presented herein. The contents do not necessarily reflect the official views or policies of the Virginia Department of Transportation, the Commonwealth Transportation Board, or the Federal Highway Administration. This report does not constitute a standard, specification, or regulation.

Each contract report is peer reviewed and accepted for publication by Research Council staff with expertise in related technical areas. Final editing and proofreading of the report are performed by the contractor.

Copyright 2008 by the Commonwealth of Virginia.

All rights reserved. 


\begin{abstract}
In the last decade, the application of image-based evaluation of particle shape, angularity and texture has been widely researched to characterize aggregate morphology. These efforts have been driven by the knowledge that the morphologic characteristics affect the properties and ultimate performance of aggregate mixtures in hot-mixed asphalt, hydraulic cement concrete and bound and unbound pavement layers, yet the lack of rapid, objective, and quantitative methods for assessment have inhibited their application in the engineering process. Developed systems for computer-based imaging and image analysis can cost up to \$30-40,000 and are usually not portable to the field. However, recent advances in technology have produced pocket computers having as much processing power as was available in some desktop computers. This project takes advantage of these advances to develop an inexpensive portable image analysis system for characterizing aggregate morphology. The system was developed with an integral pocket computer-high resolution camera but can also use individual components consisting of a digital camera and lap- or desk-top computer.
\end{abstract}

Digital images of aggregate particles are captured with the camera. These images are analyzed within the Matlab software program environment with a macro developed and written for this project that uses Fast Fourier Transform to characterize the particle morphology with respect to three parameters: shape, angularity and texture, based on the particle perimeter (outline or edge). By analyzing a number of particles from a source, it can be characterized with respect to these three parameters.

Following development of the analysis program, 10 coarse aggregates from various Virginia sources were analyzed. Particles of each aggregate were randomly chosen so that each group contained the various shapes and textures representative of the source. Three images of each particle were obtained at distances of 2,3, and 10 in to evaluate the resolution needed for adequate analysis. The reliability of the image processing was assessed by statistically analyzing the shape, angularity, and texture values to determine how the threshold parameter affects the particle edge acquisition. Asymptotic analysis was performed to determine the number of images needed to obtain a statistically stable value for each aggregate parameter.

It was determined that images acquired at close range ( 2 or 3 in) were needed to provide sufficient resolution to adequately characterize the aggregate. It was also found that statistically valid values for aggregate shape, angularity, and texture can be obtained from fifteen particle images of random orientation. It can be concluded that the system can be successfully used to characterize coarse aggregate morphology.

It is recommended that the Virginia Department of Transportation's Materials Division begin collecting images of aggregates used statewide and collaborate with the VTRC to perform the characterizations and build the database of aggregate morphologic characteristics. This information, coupled with performance testing of the materials, will provide the basis for incorporating the characterization parameters into specifications and guide material usage in the future. 
FINAL CONTRACT REPORT

\title{
PORTABLE IMAGE ANALYSIS SYSTEM FOR CHARACTERIZING AGGREGATE MORPHOLOGY
}

\author{
Linbing Wang, Ph.D., P.E. \\ Associate Director \\ Center for Sustainable Transportation Infrastructure \\ Virginia Tech Transportation Institute \\ D. Stephen Lane \\ Associate Principal Research Scientist \\ Virginia Transportation Research Council \\ Yang Lu \\ Graduate Student \\ Department of Civil and Environmental Engineering \\ Virginia Tech \\ Cristian Druta, Ph.D. \\ Research Associate \\ Center for Sustainable Transportation Infrastructure \\ Virginia Tech Transportation Institute
}

\section{INTRODUCTION}

Mineral aggregates are by far the largest volumetric constituent in both asphalt concrete and hydraulic cement concrete. As such, their shape, angularity, and texture characteristics have a significant influence on the rheological properties (i.e., compactability, consolidation, and workability) of these mixtures. In turn, these characteristics impact the performance of in-place asphalt and hydraulic cement concrete, as well as aggregate mixtures in treated base, and/or unbound base/subbase courses either directly by influencing bond strength with binders or shear strength, or indirectly by forcing on-the-job adjustments in binder content or quality. However, the coherent and comprehensive use of morphologic characteristics in engineering processes has been impeded because the methods available were often laborious and subjective, and lacked a clear connection to performance.

Computer imaging is a field that grows continuously, with new applications developing at a very fast pace (Al-Rousan et al. 2005; Masad et al. 2007a). It became a very attractive and challenging area for many people in different working domains, engulfing biology, medicine, engineering, agriculture, and many other fields. In civil engineering, computer image analysis has been extensively researched in the last decade to characterize the properties of construction materials including mineral aggregates. Thus, imaging and image analysis and processing provide a relatively simple means to obtain objective and quantitative measures of aggregate morphological (size, shape, angularity, and surface texture) characteristics. Various methods 
have been developed to quantify these aggregate parameters, with each method providing its own variation to the theme.

With the ability to characterize aggregate morphology, future efforts can focus on delineating the actual impact these parameters have on the performance of aggregates in various applications. Such information will provide the basis for realistic performance-based specifications and guide the engineering of aggregate materials for use in highway construction and rehabilitation.

In this study, a Matlab 6.5 (The Mathworks 2004)-based program is developed to characterize the aggregate morphology from digital images of aggregate particles. It uses the unified Fourier analysis to process images acquired with a digital camera providing three index values for shape, angularity, and texture.

\section{PURPOSE AND SCOPE}

The morphological properties of aggregate particles at macro scale, i.e., shape, angularity, and surface texture, are basically variations of asperities at different dimensional scales and they affect the bulk aggregate (mixture of particles) properties in different ways. These properties are believed to be related to the performance of aggregates in various applications, such as rutting and/or cracking in asphalt pavements. Specifications based on engineering intuition are currently used to control the flat, elongated, and rounded aggregates in asphalt mixes. Recent developments in automated aggregate imaging methods provide a more refined and quantitative way to measure these properties. The scope of this project is limited to the development of a portable image analysis system to characterize aggregate morphology. If successful, future work will be needed to validate the characterization method on a broad range of aggregates and establish a database that can be coupled with laboratory and field performance testing to establish the scientifically based relationship between aggregate morphology and performance. The ultimate goal is to provide an easy-to-use tool that increases our capability to engineer the use of aggregate materials in highway construction.

Therefore, the primary objective of this project was to develop a feasible test method to measure aggregate morphology on a routine basis, in the field. The study then focused on addressing two fundamental challenges:

1. whether the characterization will yield shape indices that are consistent with qualitative ranking or evaluation; and

2. whether the shape indices obtained for a particle in differs significantly according to the orientation of the particle when imaged (Wang et al. 1997).

To address these issues, the developed method was used to evaluate the morphological characteristics of 10 different aggregates provided by the Virginia Transportation Research Council (VTRC) and the results were statistically analyzed. 


\section{METHODS AND MATERIALS}

Particle shape, texture, and angularity are among the aggregate properties that have significant effects on pavement performance (Fletcher et al. 2002; Atkins 2003). In the case of coarse aggregates, the aforementioned properties are critical factors influencing the permanent deformation and fatigue characteristics of pavements by affecting the workability, density, stability, durability, and permeability of the asphalt concrete mixes. These properties also vary widely with the type and source of aggregates and processing variables. For asphalt mixes, it is preferable to use cubical and angular particles over flat and/or elongated, or rounded particles. Flat and/or elongated particles have the tendency to break during construction and under traffic loads and smooth, rounded particles fail to provide sufficient internal friction or achieve a strong bond with the binder. However, current aggregate specifications do not address, in a direct manner, the measurement of these properties, thus leading to inconsistent interpretation and use of test results (Pan and Tutumluer 2006).

For this research, 10 types of coarse aggregates from different sources and with different sizes were used for evaluation. They were selected to cover a wide spectrum of origin, rock type, and characteristics. All the aggregates were from various quarries and plants across Virginia and were provided by the VTRC. Their sources and types are shown in Table 1.

Table 1. Coarse aggregate sources and sizes

\begin{tabular}{|l|c|c|c|c|c|c|}
\hline \multirow{2}{*}{ Aggregate source } & \multirow{2}{*}{$\begin{array}{c}\text { Aggregate } \\
\text { description }\end{array}$} & \multicolumn{5}{c|}{ Aggregate sizes (mm) } \\
\cline { 4 - 8 } $\begin{array}{l}\text { Piney River, Boxley } \\
\text { Aggregates }\end{array}$ & Aplite/Granite & & $\mathrm{37}$ & $\mathrm{x}$ & $\mathrm{x}$ & $\mathbf{1 9 . 5}$ - 4.75 \\
\hline $\begin{array}{l}\text { Red Hill, Martin } \\
\text { Marietta Aggregates }\end{array}$ & Granitic gneiss & & $\mathrm{x}$ & $\mathrm{x}$ & $\mathrm{x}$ & \\
\hline $\begin{array}{l}\text { Puddledock, Vulcan } \\
\text { Materials Company }\end{array}$ & Quartz gravel & & $\mathrm{x}$ & $\mathrm{x}$ & $\mathrm{x}$ & \\
\hline $\begin{array}{l}\text { Augusta, Luck Stone } \\
\text { Corporation }\end{array}$ & Limestone & & $\mathrm{x}$ & $\mathrm{x}$ & $\mathrm{x}$ & \\
\hline $\begin{array}{l}\text { King William, Luck } \\
\text { Stone Corporation }\end{array}$ & Quartz gravel & & $\mathrm{x}$ & $\mathrm{x}$ & $\mathrm{x}$ & \\
\hline $\begin{array}{l}\text { Powhatan, Luck Stone } \\
\text { Corporation }\end{array}$ & $\begin{array}{c}\text { Amphibolite/ } \\
\text { Granite }\end{array}$ & & $\mathrm{x}$ & $\mathrm{x}$ & $\mathrm{x}$ & $\mathrm{x}$ \\
\hline $\begin{array}{l}\text { Chantilly Crushed } \\
\text { Stone Inc. }\end{array}$ & Diabase & $\mathrm{x}$ & $\mathrm{x}$ & $\mathrm{x}$ & $\mathrm{x}$ & \\
\hline $\begin{array}{l}\text { Jack Quarry, Vulcan } \\
\text { Materials Company }\end{array}$ & Granite & & $\mathrm{x}$ & $\mathrm{x}$ & $\mathrm{x}$ & $\mathrm{x}$ \\
\hline $\begin{array}{l}\text { Appomattox Lime } \\
\text { Company }\end{array}$ & Marble & $\mathrm{x}$ & $\mathrm{x}$ & $\mathrm{x}$ & $\mathrm{x}$ & \\
\hline $\begin{array}{l}\text { Stuarts Draft, Brett } \\
\text { Aggregate Inc. }\end{array}$ & $\begin{array}{c}\text { Arkose/ } \\
\text { Quartzite }\end{array}$ & $\mathrm{x}$ & $\mathrm{x}$ & $\mathrm{x}$ & $\mathrm{x}$ & \\
\hline
\end{tabular}

For the aggregates described in Table 1 image analysis and processing were performed only on individual particles regardless of their size. Fifteen profile images were acquired for each type of aggregate in order to cover a broad range of shapes in their stable and less stable positions. As it is well known that shape, angularity, and surface texture of crushed stone and uncrushed gravel may vary considerably, the proposed analysis method is useful for engineers to 
rapidly analyze any changes in aggregate physical characteristics. The analysis method would be part of the quality assurance (QA) and quality control (QC) procedures in the field. The following sections provide more details about the analysis method and operations of the pocket computer system.

\section{Aggregate Image Acquisition and Processing System}

With the advent of digital image analysis and processing techniques, more and more researchers are trying to employ an automated aggregate shape characterization approach (Lanaro and Tolppanen 2002). A number of these techniques, such as X-ray tomography or laser profiling have been tried, as they are fast and therefore can be applied as real-time quality control. These advances provide the means for the development of automated methods for aggregate shape analysis based on measurements made directly from the individual aggregate (Hossain et al. 2000; Rao et al. 2001; Al-Rousan et al. 2006; Masad et al. 2007b).

Computer imaging systems are made in many different configurations, depending on the type of application. But, as technology advances these systems are getting smaller, faster, and in some cases quite sophisticated. The computer imaging system used in this study was a Sony VAIO micro (pocket) computer with a built-in digital camera of $1.3 \mathrm{M}$ pixel resolution. A picture of the micro computer is shown in Figure 1. Because this is a full-functioning PC using Microsoft XP operating system, application user interfaces are familiar and easy to use. For rapid field image analysis of coarse aggregates, Matlab 6.5 software was installed on it.

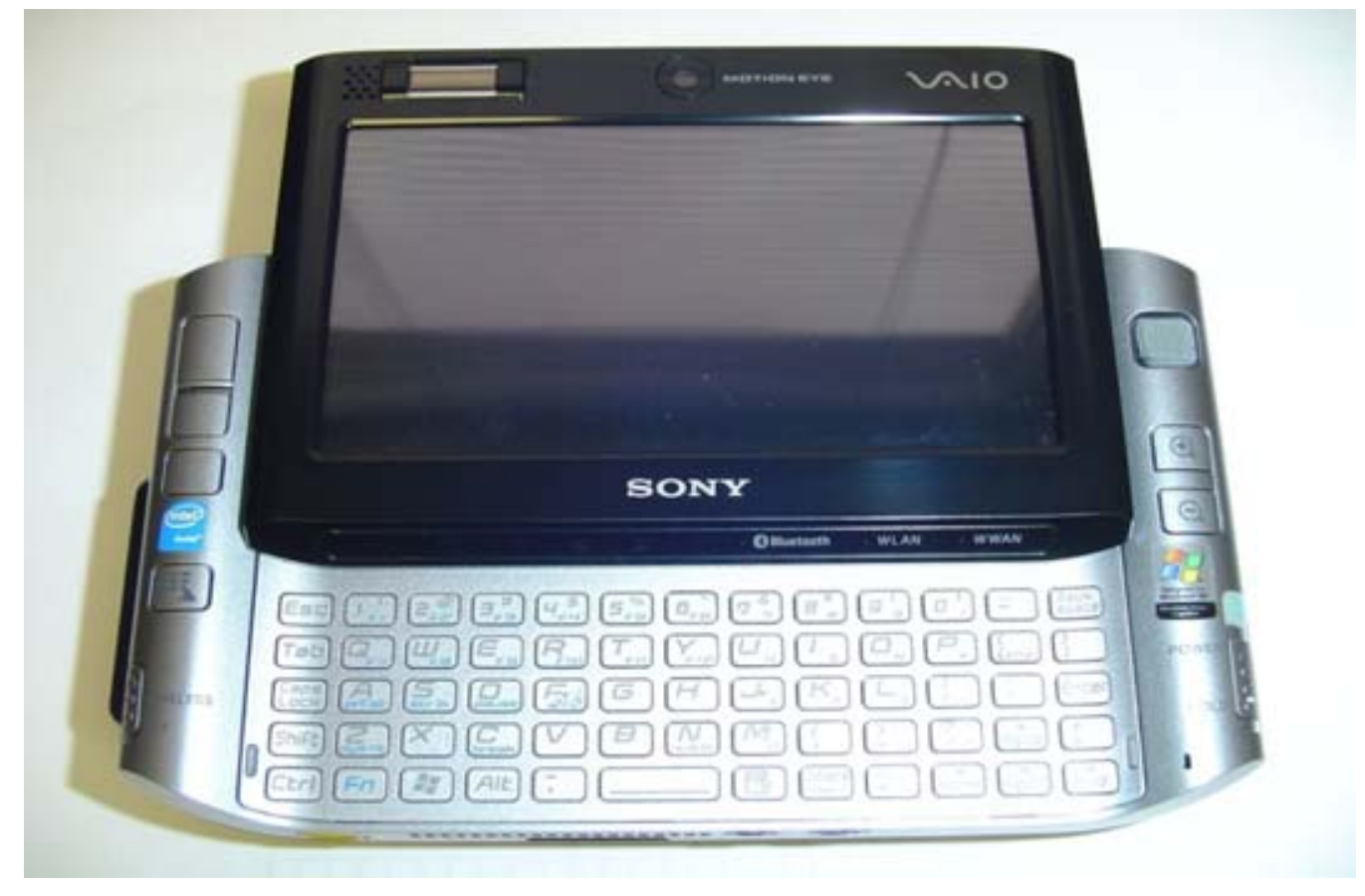

Figure 1. Micro computer imaging system Sony VAIO UX280P

Aggregate images acquired with the digital camera are easy to process with the help of a program code written in Matlab. The micro computer is designed to be versatile enough to 
capture images at different resolutions, fields of view, and using different lighting schemes in order to be able to analyze the form, angularity, and texture of mineral aggregates.

\section{Computer Imaging Background}

Computer imaging can be defined as the acquisition and processing of visual information by computer. The importance of this technique was derived from the fact that the primary human sense is visual, and the information that can be conveyed in images could be easily processed with the newly developed software. The software allows us to manipulate or process the images to "highlight" specific information, pull that information as image data and then perform the desired analysis on that data. Additionally, specialized software can be used to control the image acquisition and storage process.

Depending on the ultimate "user" of the visual information, computer imaging can be divided into two principal applications areas: (1) computer vision, and (2) image processing, with image analysis being a key component in the development and display of both. In computer vision applications, the processed or output images are for use by a computer, while in image processing applications, the resulting images are for human interpretation (Umbaugh 2005). Figure 2 presents a schematic representation of the computer imaging concept.

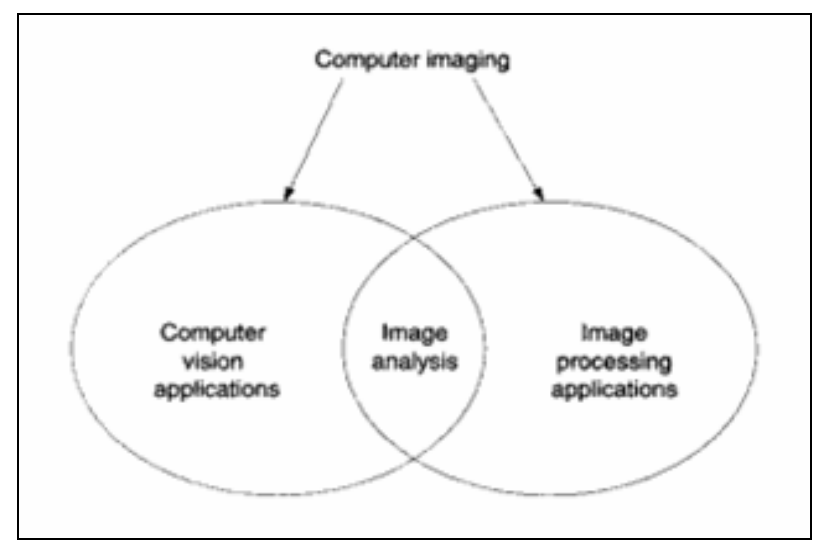

Figure 2. Computer imaging representation

\section{Development of the Aggregate Morphological Analysis Method}

Typically, image analysis involves the examination of the image data to facilitate solving an imaging problem. The image analysis methods comprise the major components of the computer vision system, if the system has to analyze the images and have a computer act on the results. When developing an image processing algorithm or system, many images have to be examined, so image analysis is necessary during the development of an image processing system. 
The shape, angularity, and surface texture are three related properties in aggregate morphological analysis, as shown in Figure 3. These properties represent spatial variations (irregularities) of different dimensional scales. Shape represents variation in the large dimension; angularity represents variation in the medium dimension superimposed on shape; and surface texture represents variation in the small dimension superimposed on angularity.

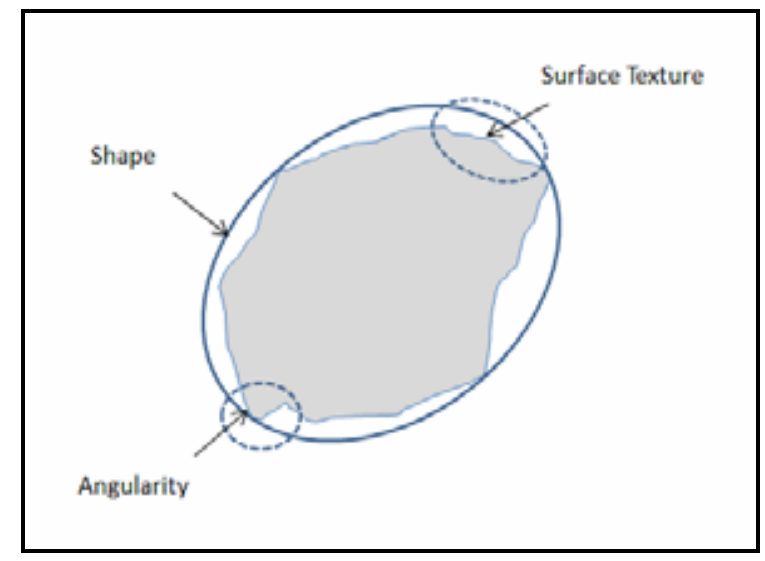

Figure 3. Coarse aggregate shape properties

In the frequency domain, large spatial variations are related to low frequency and small spatial variations are related to large frequency. Due to their different dimensions, shape, angularity, and surface texture affect material properties in different ways. As an example, the local curvature of particles at their contact is very important in the load transfer within the aggregate skeleton, while the surface texture at the interface between aggregates and binder is important for durability. Because these three aggregate properties have to be dealt with separately, this can only be done with the employment of a method that efficiently analyzes each one of them. In this respect, one of the most appropriate methods is the Fourier morphological analysis based on spatial frequency characteristics.

An aggregate particle profile, as shown in Figure 4, can be represented in the following equation as a Fourier series:

$$
R(\theta)=a_{0}+\sum_{m=1}^{\infty}\left(a_{m} \cos m \theta+b_{m} \sin m \theta\right)
$$




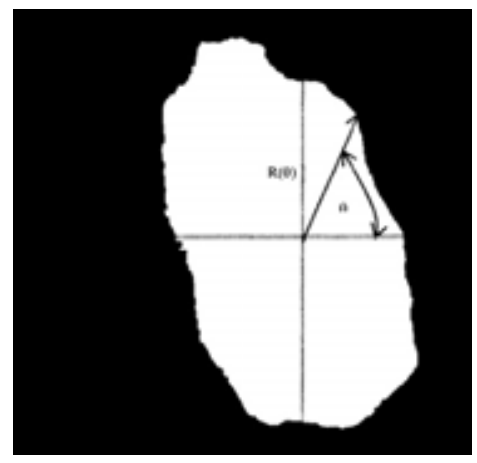

Figure 4. Illustration of Fourier boundary representation (Wang et al. 2005)

In this expression, the origin of the coordinate system is placed at the center of gravity for consistency. In classical Fourier analysis of particle profiles, the following three parameters are used to describe the shape (lumpiness), angularity (roughness), and surface texture of a particle profile in the form of an equation.

$$
\begin{aligned}
\alpha_{\mathrm{s}} & =\frac{1}{2} \sum_{m=1}^{m=n 1}\left[\left(\frac{a_{m}}{a_{0}}\right)^{2}+\left(\frac{b_{m}}{a_{0}}\right)^{2}\right] \\
\alpha_{\mathrm{r}} & =\frac{1}{2} \sum_{m=n 1+1}^{m=n 2}\left[\left(\frac{a_{m}}{a_{0}}\right)^{2}+\left(\frac{b_{m}}{a_{0}}\right)^{2}\right] \\
\alpha_{\mathrm{t}} & =\frac{1}{2} \sum_{m=n 2+1}^{m=\infty}\left[\left(\frac{a_{m}}{a_{0}}\right)^{2}+\left(\frac{b_{m}}{a_{0}}\right)^{2}\right]
\end{aligned}
$$

In the above 3 equations $\mathrm{n} 1$ and $\mathrm{n} 2$ represent threshold frequencies separating shape, angularity, and surface texture factors, respectively. In practice, $\left(1+\alpha_{s}\right)$ is used as the shape factor so that a perfect circle will have a shape factor of 1 .

If different combinations of $a_{m}, b_{m}$ are used in Equation (1) various complex shapes can be obtained for a particle. Figure 5 illustrates how different frequencies $(m)$ and magnitudes $a_{m}$, $b_{m}$ contribute to the profile shape, angularity, and surface texture. For simplification, only $\left(a_{0}+\right.$ $a_{m} \cos m \theta$ ) is plotted in Figure 5. All the shapes were plotted for an average radius $a_{0}$ equal to 100 units. A triangular shape (Figure 5a) and a square shape (Figure 5b) were obtained for $\mathrm{m}=3$ and 4 , respectively. 


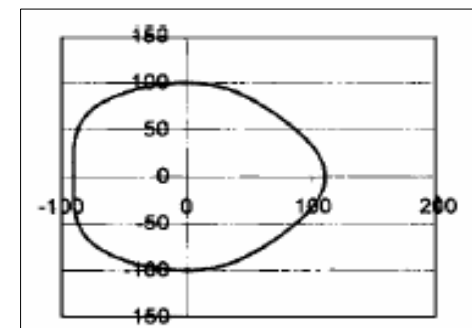

(a)

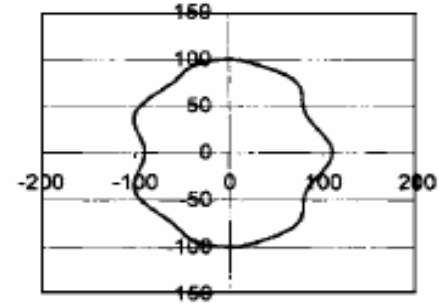

(c)

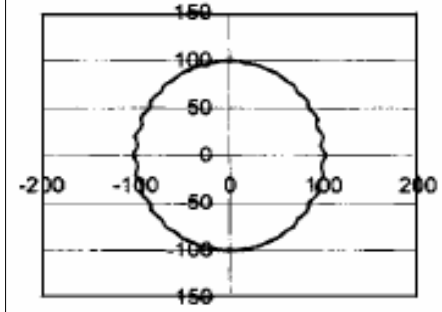

(e)

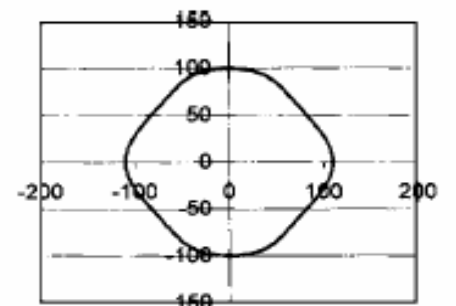

(b)

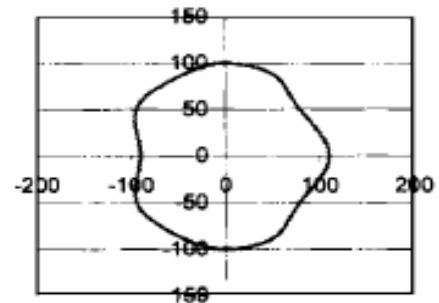

(d)

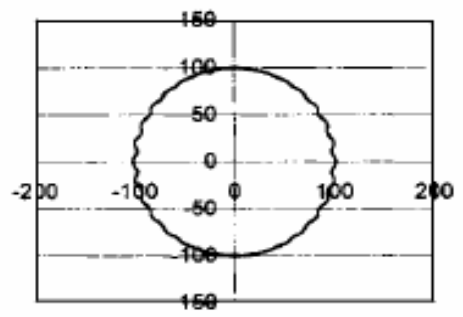

(f)

Figure 5. Frequency and magnitude effect on profile parameters

For $m \geq 5$, Figure 5 (c and d) represent multiple corners, simulating the angularity of aggregate profiles, but when $m>25$, the frequency is so large that corners become very close to each other as shown in Figure 5 (e and $\mathrm{f}$ ). These corners are not considered to contribute to angularity qualitatively by human judgment. The above observations indicate that terms with 5 $\leq \mathrm{m} \leq 25$ contribute significantly to angularity, while terms with $\mathrm{m}>25$ can be considered to contribute to surface texture. Therefore, the low frequency terms $(1 \leq \mathrm{m} \leq 4)$ are named shape terms, the medium-frequency terms $(5 \leq \mathrm{m} \leq 25)$ angularity terms, and high-frequency terms $(\mathrm{m}>25)$ surface texture terms. Typically, large magnitude and low frequency in the Fourier representation are related to shape of the boundary, while small magnitude and high frequency are related to angularity and surface texture.

Because the characteristics of the Fourier coefficients prevent the combination of large magnitude and large frequency, as the coefficients must satisfy certain restricting conditions, it can be concluded that at high frequencies the coefficients $a_{m}$ and $b_{m}$ should be very small, which is consistent with the physical implication of angularity and surface texture. Hence, the above findings indicate that $n 1=4$ and $n 2=25$ are appropriate values. Finding the threshold frequency $n 3$ involves another rationale, as the surface texture is related to spatial variations as small as a micrometer and even smaller. In this light, the quantitative measurements must be consistent with the qualitative human judgment based on observations made with unaided eyes. The fact that the real spacing discernible by human eyes is $0.2 \mathrm{~mm}$ (Wang et al. 2005) means that variation frequency (peak to trough) should not be larger than $180 \mathrm{deg}$ for a particle of $25 \mathrm{~mm}$ in 
diameter. As the perimeter of a particle with a diameter of $25 \mathrm{~mm}$ is roughly $80 \mathrm{~mm}$ and the sampling space is $1 \mathrm{deg}$ (peak to trough), then the spacing between the two boundary points is about $0.22 \mathrm{~mm}$. Sampling spacing smaller than $1 \mathrm{deg}$ would not be discernible to unaided eyes, which means $m=180$, because peak-trough spacing is $\pi$ for sin and cos functions. In other words, the total number of peak and trough points at the surface would be 360 . If the image resolution is too small, for example, larger than $0.2 \mathrm{~mm} /$ pixel, then the surface texture cannot be adequately evaluated. All these values were incorporated in the Matlab 6.5 program for rapid field evaluation of coarse aggregates.

\section{Operating Procedures}

As shown in Figure 8, the first step of the aggregate image analysis is taking a picture of an aggregate particle (Figure 6) with a digital camera. This is a critical step, because the raw image data are provided by this picture. To achieve high resolution of the particle perimeter, it is recommended that the aggregate be placed on a background (e.g., black or white) that provides sufficient contrast with the aggregate particle as shown in Figure 7. The program code written in Matlab 6.5 is installed on the computer and is powerful enough for processing any color format such as RGB or Grayscale, as well as various image formats, such as JPG and BMP. The analysis process starts by clicking on the Save \& Run button in the Matlab working environment after indicating in the program code the name of the picture taken followed by the extension (JPG or BMP).

In the second step the acquired image is converted to binary image. During this step, the recognition threshold value (e.g., 0.6) in im $2 \mathrm{bw}(*, 0.6)$ function in the program is selected. Based on the output binary image, the operator needs to judge the threshold value, which ranges from 0 to 1.0. This is a trial-and-error procedure, as one needs to try different values until a good binary image is acquired, which correctly detects the boundary shape.

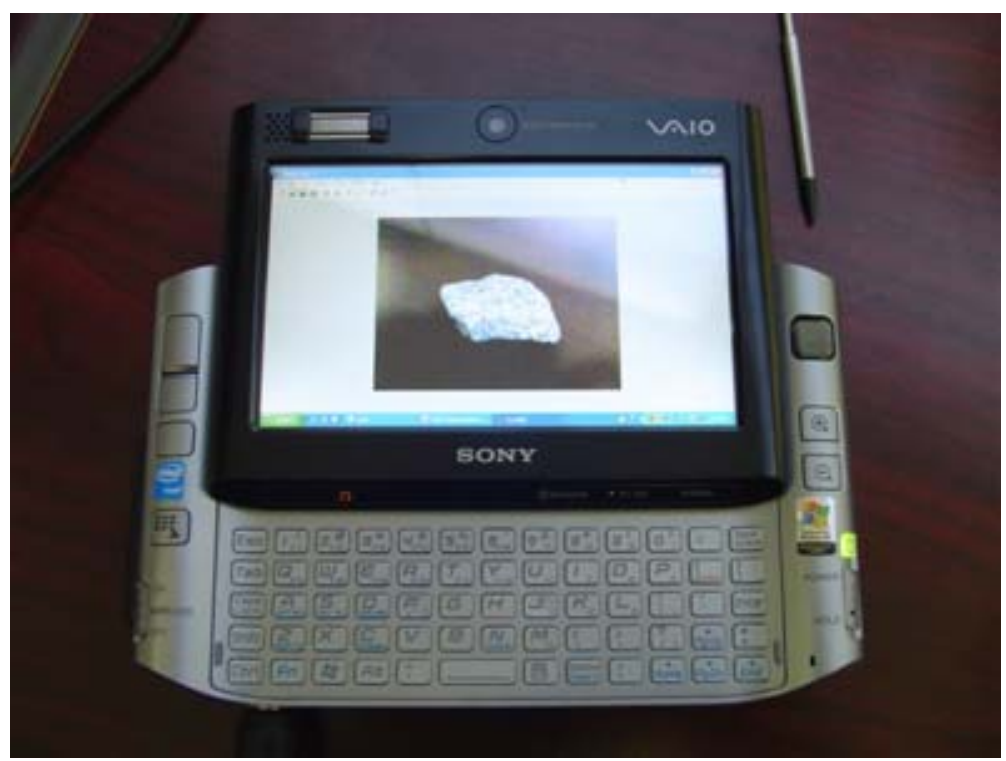

Figure 6. Raw image data acquisition 

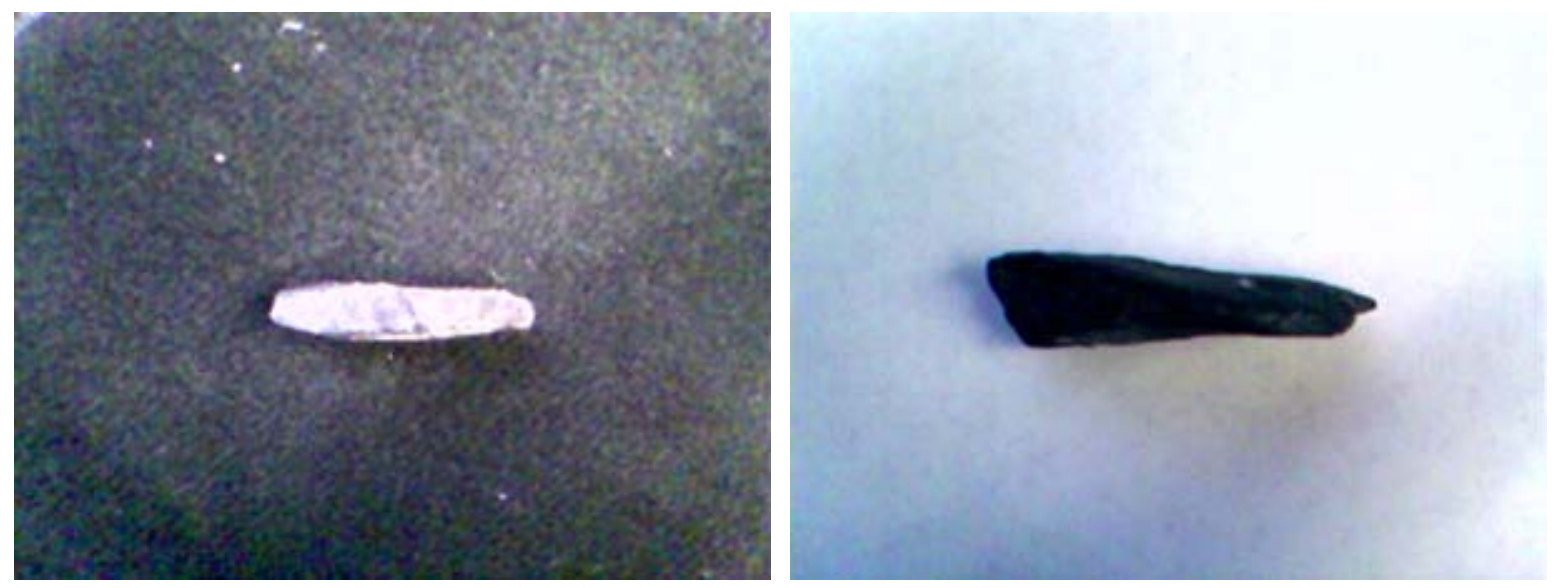

Figure 7. Positioning aggregates on different backgrounds

Figure 9 illustrates a trial-and-error binary image that contains some noise points. In general, the noise in an image is any undesired information that contaminates that image. It can appear in images from a variety of sources. One of the primary processes by which noise appears in digital images is the acquisition process. In this process an optical image is converted into a continuous electrical signal that is then sampled. Fluctuations caused by natural phenomena are present at every step of this process. They add a random value to the exact brightness value for a given pixel. Environmental conditions such as temperature are also affecting the noise already present in the electronics, as it can vary during the acquisition of an image database. Some periodic noise may be introduced during the acquisition process as a result of the physical systems involved.

As a result of the above-mentioned causes, many noise points exist in the binary image, both inside and/or outside the aggregate domain. Because of this noise, the final profile of the analyzed aggregate particle is strongly affected. In the third step of the image process, using the differentiation algorithm from the Fourier analysis incorporated in the Matlab program, the noise points are completely and accurately removed from the binary image. Figure 10 presents a noise-free picture of the aggregate particle.

After the critical noise points removal step, a restored binary image of the aggregate is acquired. Then, in the forth step, the operator visually compares the resulting image with the original image to verify if they match. This is also a very important step before the acquisition of the aggregate profile (edge) (see Figure 11) as this profile may be distorted in case the binary image does not match the original aggregate image. If a satisfactory match between the aggregate edge and the original image is achieved, then the edge profile along with the values for the shape, angularity, and texture can be saved to a designated folder. In case the particle edge does not match the original aggregate profile, steps 2 through 4 must be repeated and the threshold value modified accordingly until an almost perfect match is achieved. 


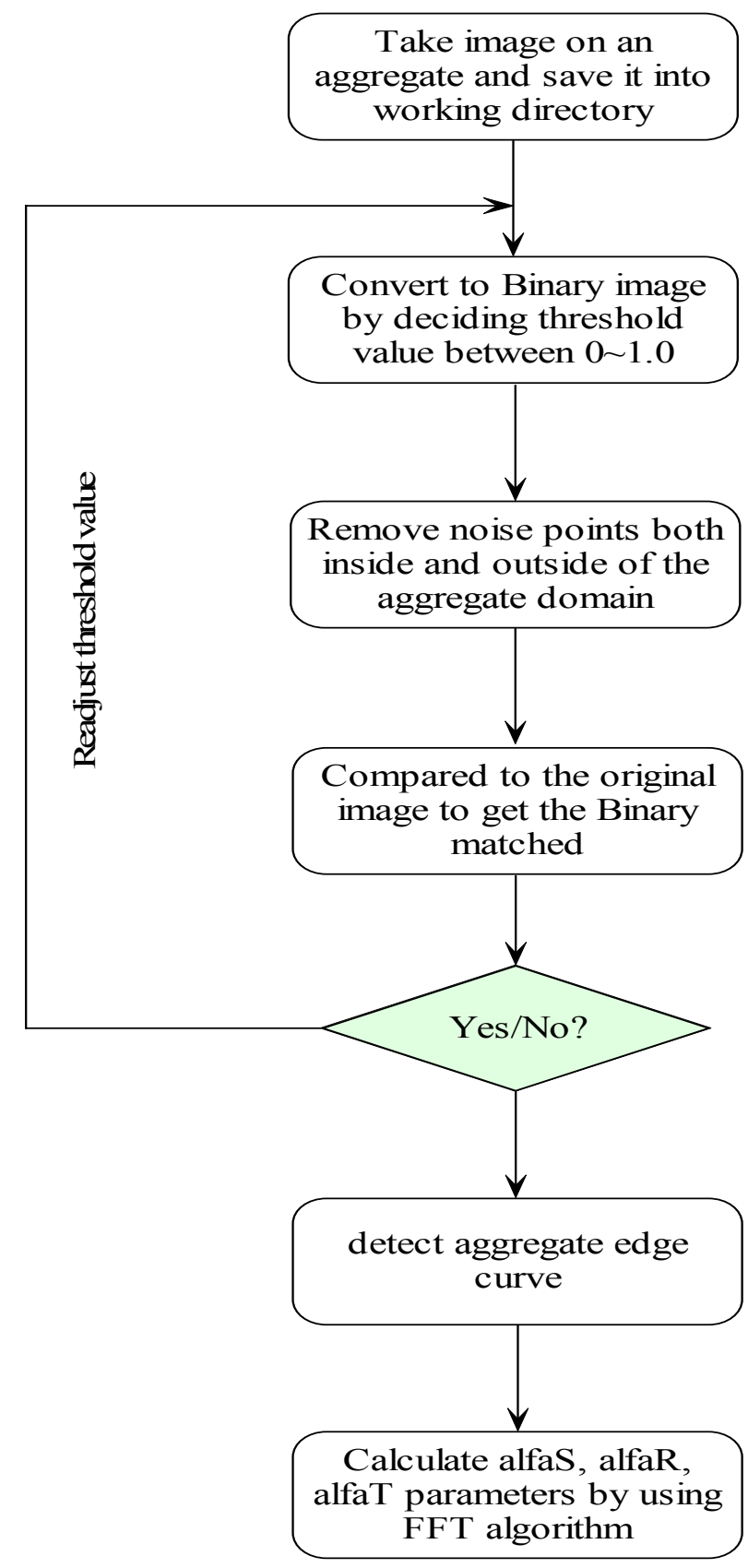

Figure 8. Aggregate morphological analysis flow chart 


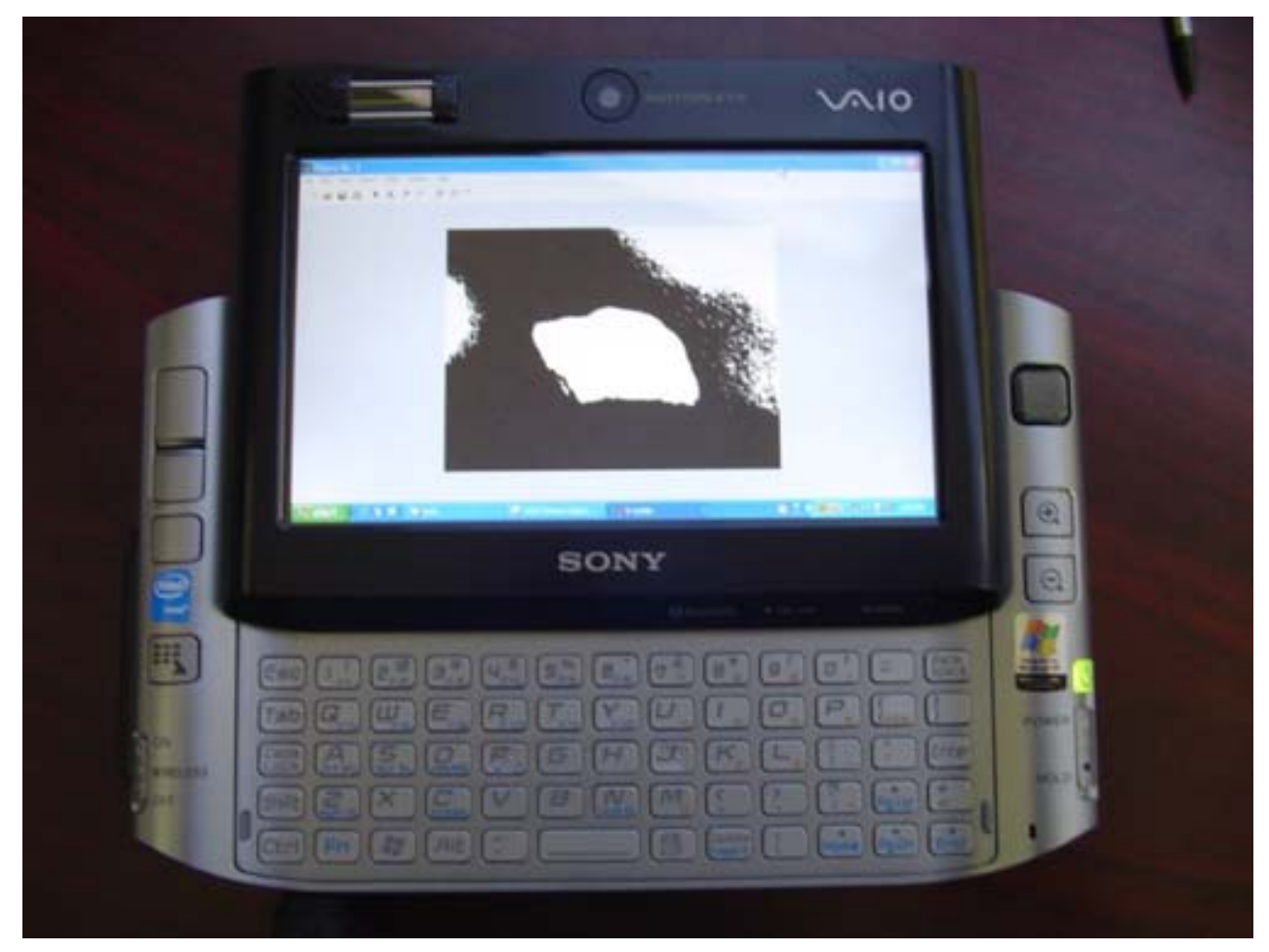

Figure 9. Noise in the binary image

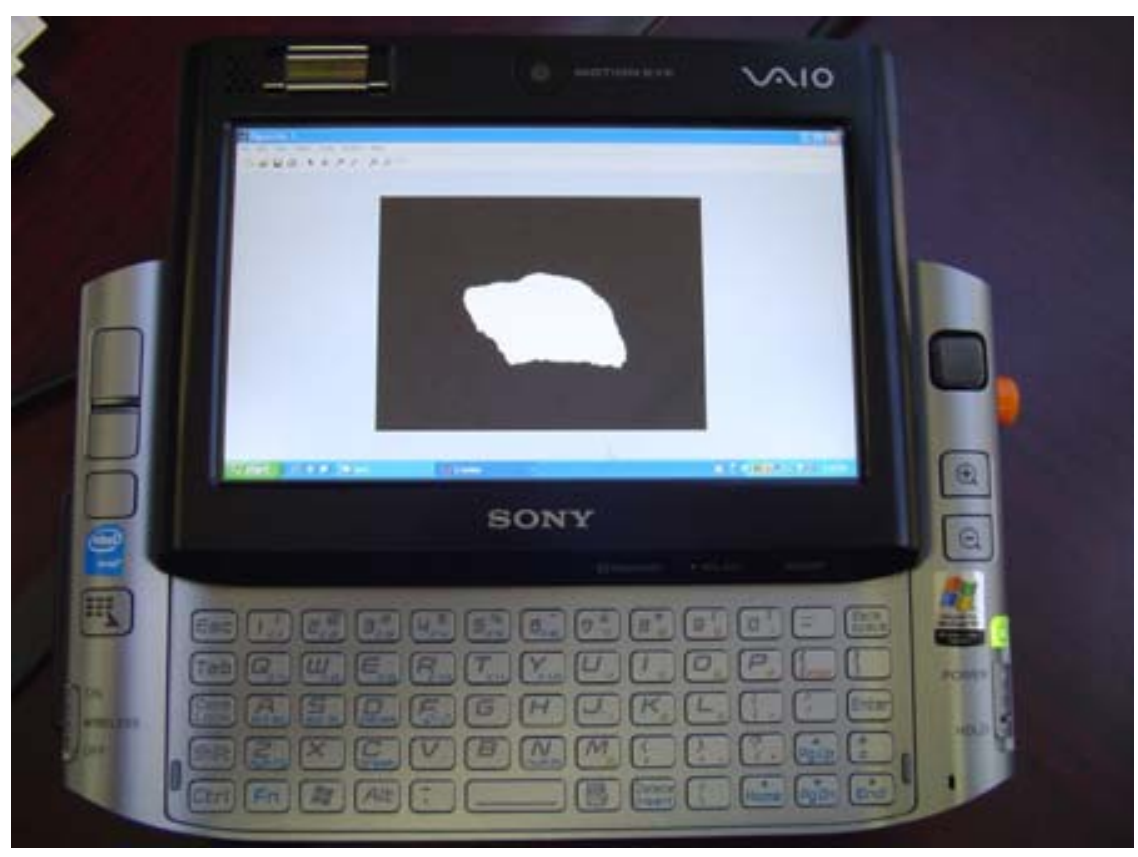

Figure 10. Noise-free aggregate particle 
As shown above, the final edge profile can be saved in the Matlab work folder together with the shape, angularity, and surface texture factors which can be copied from the Matlab command window. The Matlab image analysis code developed in this study is provided in Appendix C. The code can be simply copied and run in the work space of the Matlab environment with the results being shown in the Command Window.

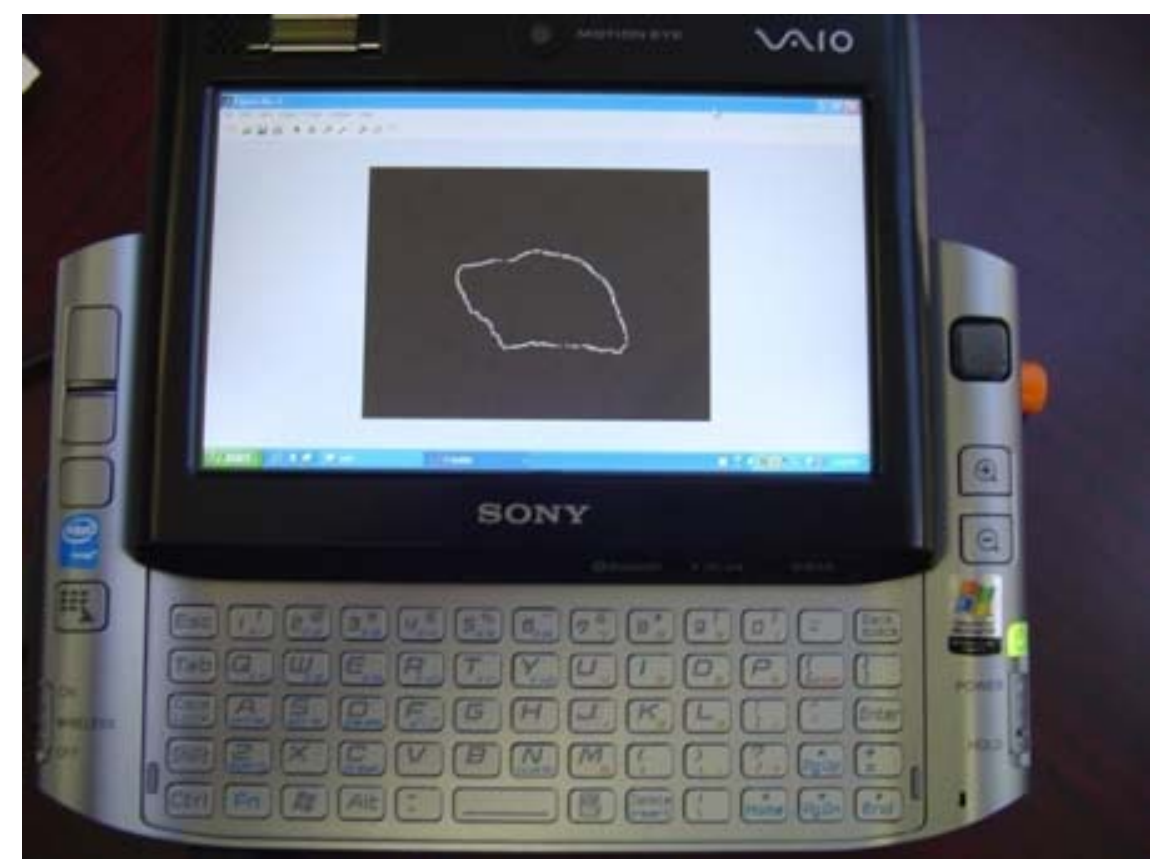

Figure 11. Aggregate profile (edge) image

The analysis procedure is not tied to the integrated camera-computer system, but can be performed using any computer which has Matlab 6.5 software (or higher) and the analysis program code developed in this study installed using images imported from any digital camera. Once the images are available to the computer, the analysis procedure follows the same steps as described for the micro computer with built-in digital camera.

\section{RESULTS AND DISCUSION}

The image analysis procedure presented in this report relies on measuring the grayscale variations of an image to quantify the coarse aggregate's shape, angularity, and surface texture of the perimeter. Fifteen pictures of each type of aggregate were taken and then analyzed using a specially developed program using Matlab 6.5 software. A total of 150 pictures were taken of particles in varying positions in order to cover the broad range of shapes that a group of particles might present in two dimensions. All the pictures acquired and their resulting profiles (edges) are presented in Appendix A. The pictures were taken at three different distances, 2 in $(5 \mathrm{~cm}), 3$ in $(7.5 \mathrm{~cm})$ and 10 in $(25 \mathrm{~cm})$ to observe the effect on the aggregate profile. The light intensity was the same in all the cases. Also, all the pictures were $640 \times 480$ pixel resolution. 
From the analyzed images (see also Appendix A) it was observed that the threshold factor, which controls the accuracy of the particle profile, was much larger when the distance from which the pictures were taken was increased and the particles became almost white. The three aggregate properties - shape, angularity, and surface texture, increased as well, with the largest values being observed for the 10 in $(25 \mathrm{~cm})$ distance. Figure 12 shows a picture of 10 different aggregates, randomly selected from each source, taken from 10 in $(25 \mathrm{~cm})$ away. It can be seen that the aggregates are much whiter than those in the pictures taken from much closer distance, as shown in Figure 13. Also, their surface texture is much more diminished compared to the other aggregates. Three aggregates from this set were analyzed separately and the results compared to the results obtained from pictures taken from a closer distance ( 2 in and/or 3 in). All the data are presented in Table 2.

Figure 14 presents the aggregates edges for pictures taken at 2 and/or 3 in and $10 \mathrm{in}$. It can be observed that the edges for pictures taken from 10 in $(25 \mathrm{~cm})$ are rougher than those taken at a closer range. This is due to the fact that the aggregates appear very small and most of the light is reflected from their surface, making them look more rugged than normal. No significant differences were observed among the aggregate edges obtained from pictures taken at 2 in and 3 in away.

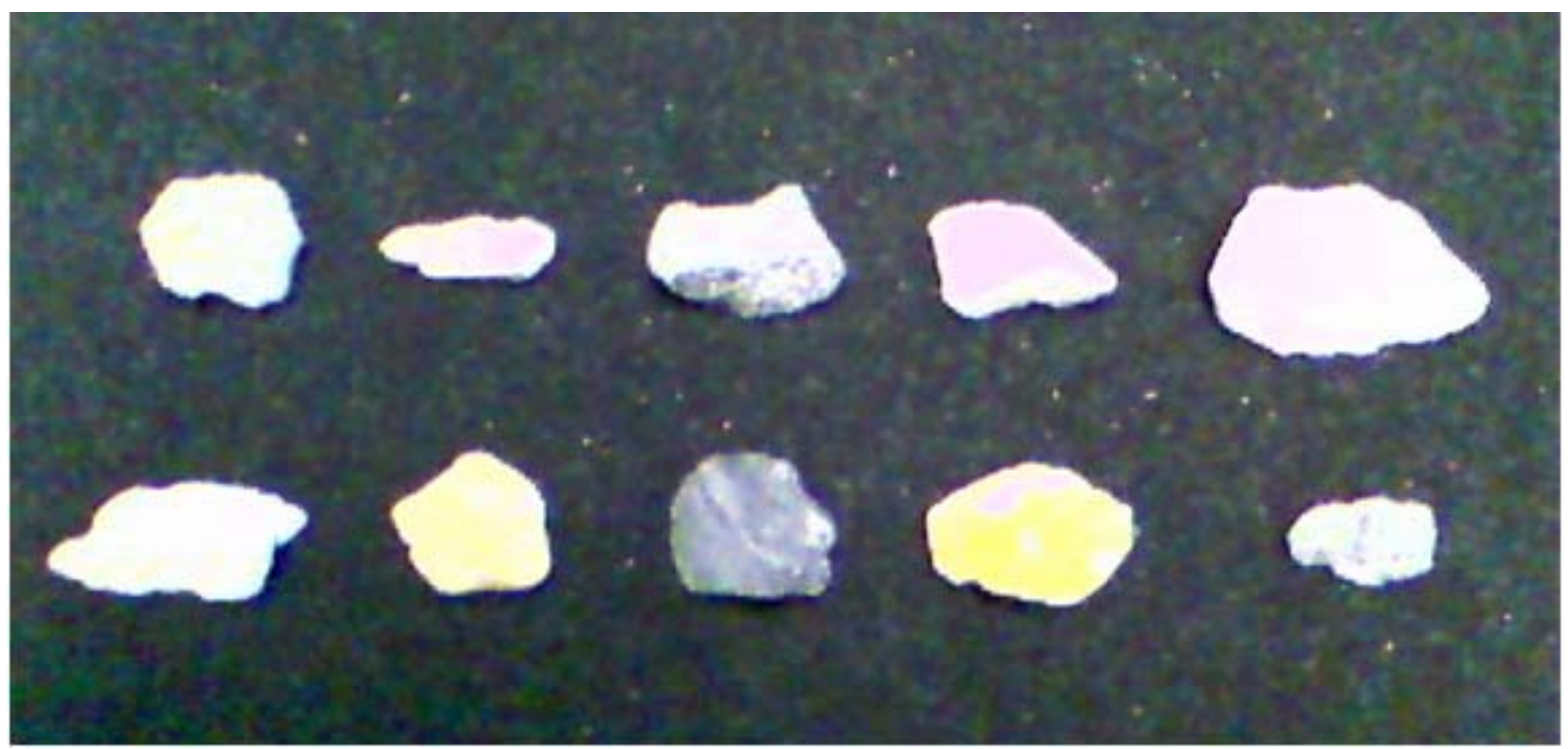

Figure 12. Aggregate picture taken at 10 in $(25 \mathrm{~cm})$ distance 

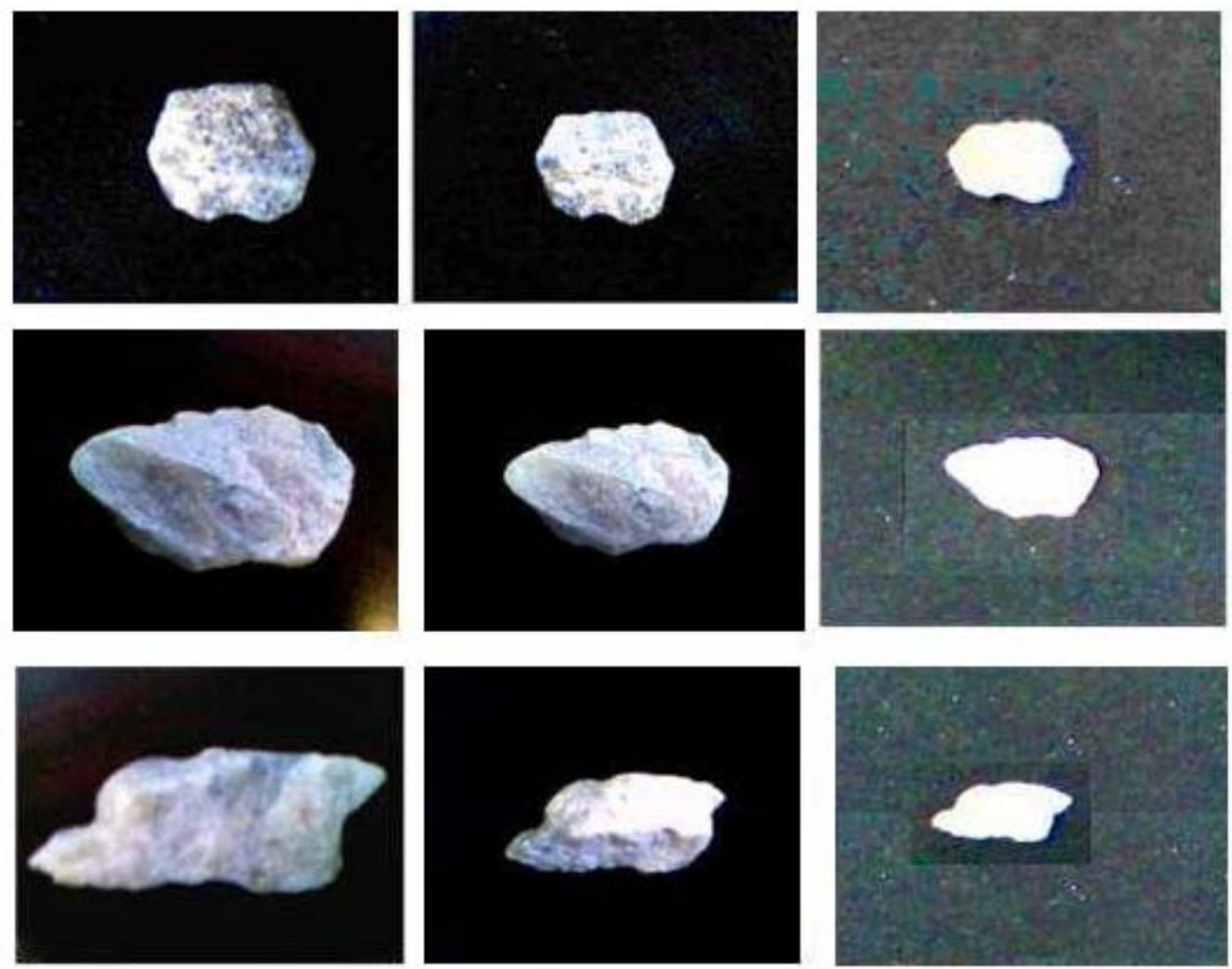

Figure 13. Aggregate pictures taken at (a) 2 in $(5 \mathrm{~cm}),(\mathrm{b}) 3$ in $(7.5 \mathrm{~cm})$, and 10 in $(25 \mathrm{~cm})$

Table 2. Aggregate profiles at three different distances

\begin{tabular}{|c|cc|c|c|c|}
\hline Picture Distance (in) & \multicolumn{2}{|c|}{ Threshold } & Shape & Angularity & Surface Texture \\
\hline \multirow{3}{*}{2} & P1 & 0.2 & 0.00085 & 0.00019 & 0.00028 \\
\cline { 2 - 7 } & P2 & 0.1 & 0.0088 & 0.00022 & 0.00094 \\
\cline { 2 - 6 } & P3 & 0.1 & 0.011 & 0.0026 & 0.0048 \\
\hline \multirow{3}{*}{3} & P1 & 0.2 & 0.001 & 0.00023 & 0.00058 \\
\cline { 2 - 6 } & P2 & 0.1 & 0.0094 & 0.00052 & 0.00071 \\
\cline { 2 - 6 } & P3 & 0.1 & 0.011 & 0.0021 & 0.0036 \\
\hline \multirow{3}{*}{10} & P1 & 0.6 & 0.0015 & 0.00077 & 0.00085 \\
\cline { 2 - 6 } & P2 & 0.6 & 0.007 & 0.00071 & 0.0015 \\
\cline { 2 - 6 } & P3 & 0.6 & 0.014 & 0.0021 & 0.0043 \\
\hline
\end{tabular}




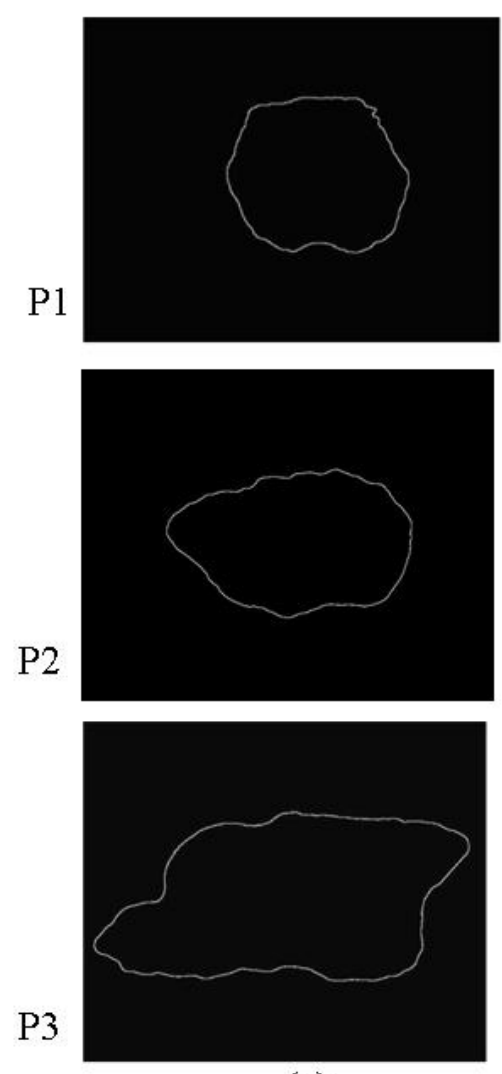

(a)
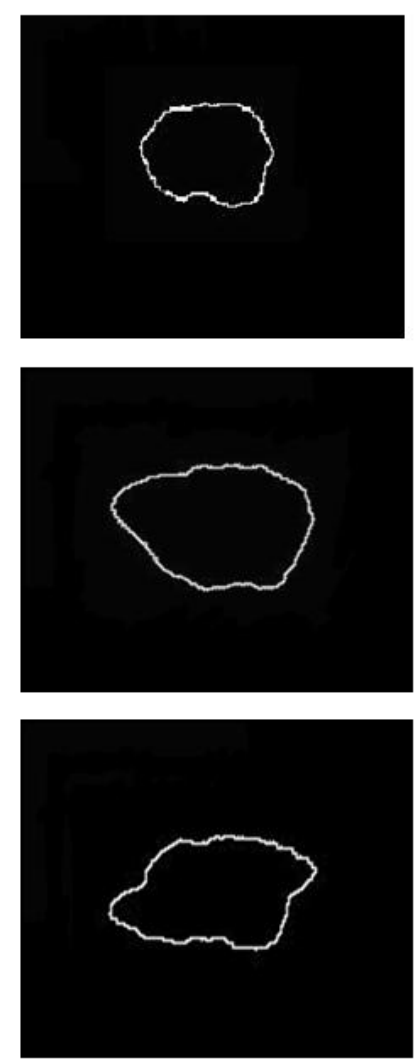

(b)

Figure 14. Aggregate profile (edge) at (a) 2 in $(5 \mathrm{~cm})$ and (b) 10 in $(25 \mathrm{~cm})$

It can be noticed from Table 2 that the aggregate parameters are in agreement with their quality. For example, all the values for particle one (the most round) (P1) are smaller than the values for the other two particles (P2 \& P3), which are more elongated.

\section{Statistical Analysis of the Aggregates Characteristics}

Statistical evaluations help engineers detect changes in aggregate physical characteristics as part of the QA/QC procedures. They also represent a good tool for assessing different aggregate crushing techniques to select those methods that produce the most desirable characteristics. In this study, statistical analysis was performed for quantifying the distribution of aggregate characteristics in the aggregate samples, and for comparing the shape characteristics of different samples. To determine if the aggregate profile characteristics were statistically different, Student's T-tests were performed among all sets of aggregate parameters by pairing them up. For better evaluation, a two-tailed distribution and unequal mean was selected at a confidence limit of 95 percent $(\alpha=0.05)$. The T-test results are shown in Appendix B. They did not indicate any significant differences among the same type of stone or source. Only four results (less than 3\%) out of 135 were statistically significant, and they were all related to the 
surface texture. They are highlighted by shading in Appendix B. Three types of aggregate limestone, granite, sandstone - were involved, coming from five different sources, thus having large variations in their textures (see Table 3).

Table 3 presents the shape, angularity, and surface texture statistics of the 10 types of aggregate analyzed. The analysis was based on the fifteen profiles acquired for each type of aggregate. It can be seen from Table 3 that the values for shape and angularity were quite consistent among the types of aggregates. As expected, larger values were acquired for granite, limestone and marble, whereas smaller values were obtained for quartz gravel, sandstone, diabase, and gneiss. Regarding the surface texture, higher values were obtained for diabase (Chantilly) and quartz gravel (Puddledock) even though their shape and angularity values were not that large. In contrast to these two types of aggregates, small texture values were obtained for marble (Appomattox) considering its relative larger shape and angularity values. The reason for these variations could be due to the arrangement of individual mineral grains of the aggregate, the crushing method, or post-crushing abrasion of the surface owing to the relatively soft mineralogy (calcite).

Table 3. Coarse aggregates mean and standard deviation

\begin{tabular}{|l|c|c|c|c|c|c|}
\hline \multirow{2}{*}{ Aggregate Source } & \multicolumn{9}{|c|}{ Aggregate Parameter } \\
\cline { 2 - 7 } & \multicolumn{2}{|c|}{ Shape } & \multicolumn{2}{c|}{ Angularity } & \multicolumn{2}{c|}{ Surface Texture } \\
\cline { 2 - 7 } & Mean & Std Dev & Mean & Std Dev & Mean & Std Dev \\
\hline Piney River (aplite/granite) & 0.0106 & 0.0092 & 0.00074 & 0.00075 & 0.00160 & 0.0021 \\
\hline King William (quartz gravel) & 0.0064 & 0.0075 & 0.00053 & 0.00067 & 0.00110 & 0.0023 \\
\hline Puddledock (quartz gravel) & 0.0050 & 0.0058 & 0.00059 & 0.0011 & 0.00097 & 0.0016 \\
\hline Augusta (limestone) & 0.0066 & 0.012 & 0.00041 & 0.0012 & 0.00085 & 0.0015 \\
\hline Jack Quarry (granite) & 0.0098 & 0.011 & 0.00100 & 0.0021 & 0.00290 & 0.0027 \\
\hline Appomattox (marble) & 0.0072 & 0.0088 & 0.00050 & 0.0039 & 0.00050 & 0.0023 \\
\hline Stuarts Draft (arkose, quartzite) & 0.0051 & 0.011 & 0.00064 & 0.00077 & 0.00088 & 0.0013 \\
\hline Powhatan (amphibolite, granite) & 0.0054 & 0.0076 & 0.00093 & 0.0016 & 0.00240 & 0.003 \\
\hline Chantilly (diabase) & 0.0047 & 0.012 & 0.00068 & 0.0029 & 0.00130 & 0.003 \\
\hline Red Hill (granitic gneiss) & 0.0034 & 0.0061 & 0.00038 & 0.0015 & 0.00081 & 0.0029 \\
\hline
\end{tabular}

Asymptotic analysis was also performed to determine if fifteen particle profiles would be enough for evaluation, so that a statistically stable value for each parameter can be obtained. Figures 15 through 17 present the asymptotic curves for shape, angularity, and surface texture for each type of aggregate. It can be seen from the figures that fifteen profiles are indeed sufficient to reach a stable value for each parameter. 


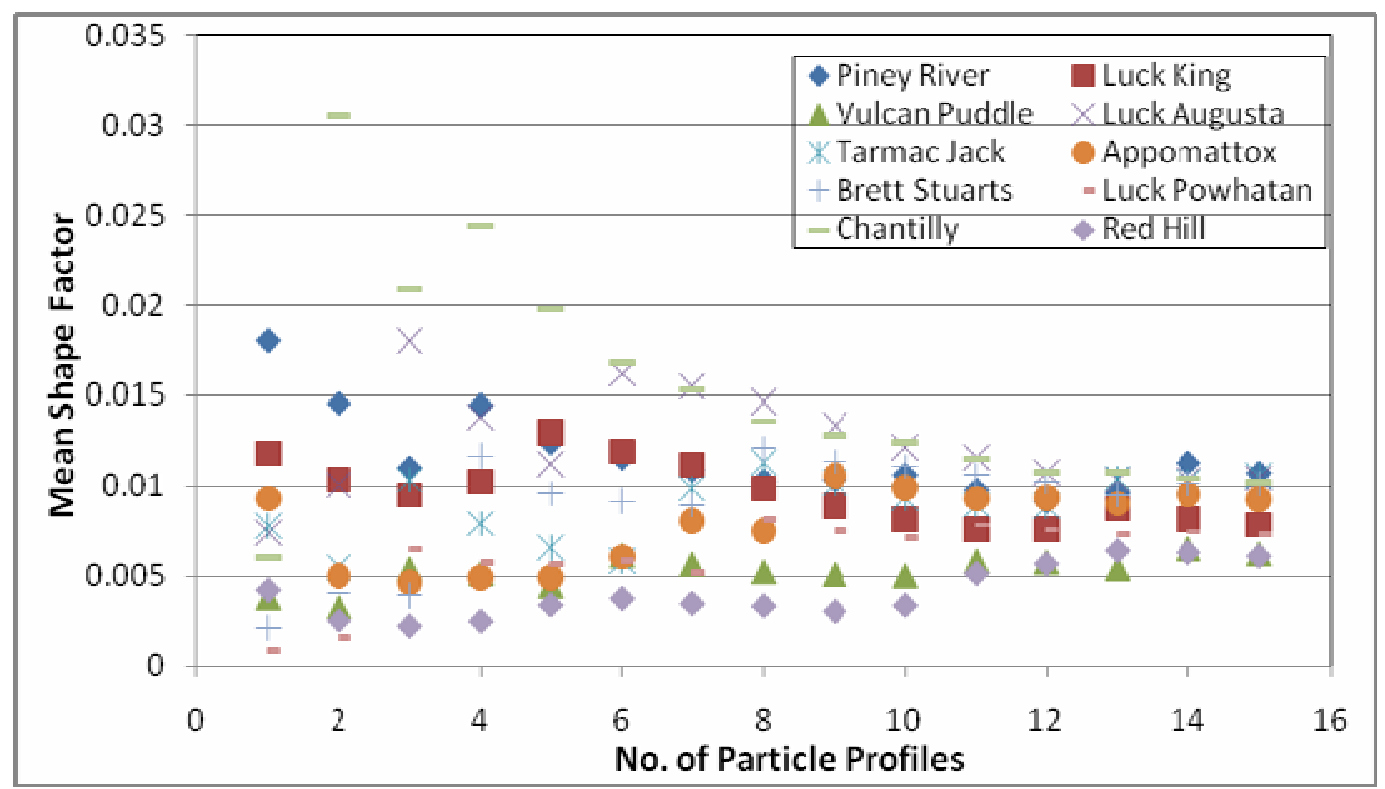

Figure 15. Aggregate shape asymptotic analysis

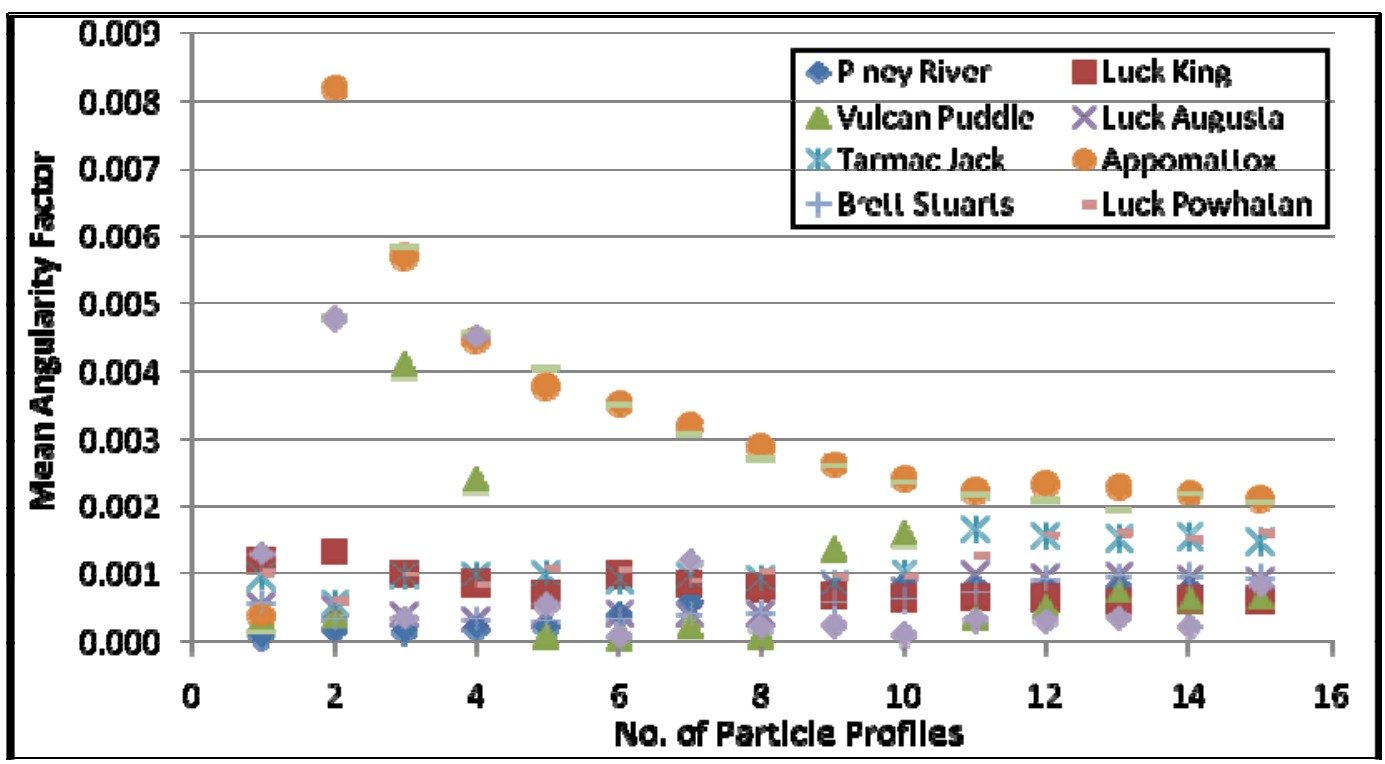

Figure 16. Aggregate angularity asymptotic analysis 


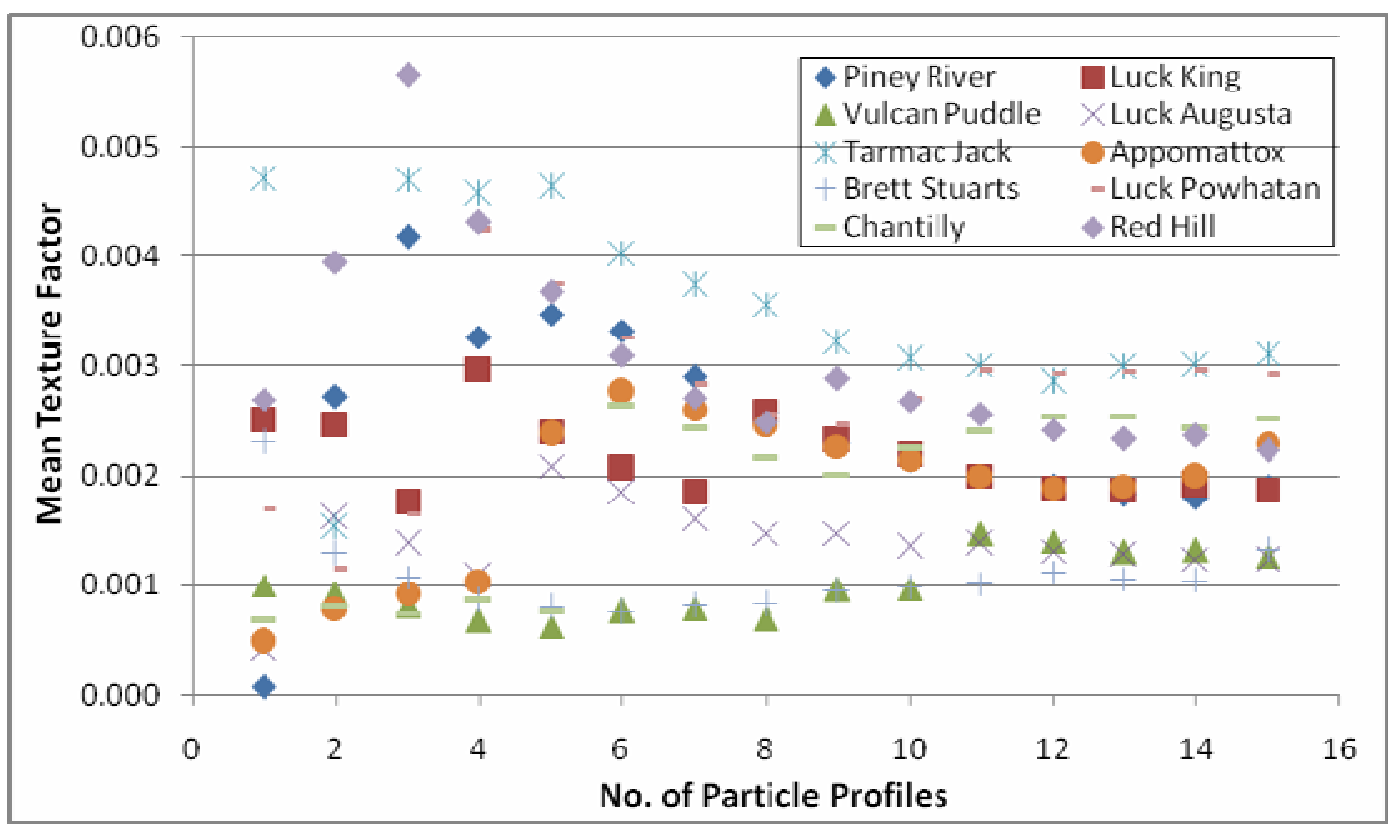

Figure 17. Aggregate surface texture asymptotic analysis

Based on the statistical test results from Table 3 it can be inferred that profile parameters are aggregate-source sensitive, as various results were obtained for each type. In this respect, a granite source showed the most elongated/angular profiles, while the lithically similar granitic gneiss showed the most rounded profiles. This could be due to the fact that during the crushing process some plants produce more flat and/or elongated aggregate particles than others.

Table 4a shows relative ranges for the three aggregate physical properties using image analysis results from Appendix A. Multiplying all values by 10,000 will give a better view of these ranges (Table $4 \mathrm{~b}$ ). They could be used as guidelines in evaluating the coarse aggregate usage for asphalt and cement concrete.

Table 4a. Coarse aggregate physical properties ranges based on their image analysis

\begin{tabular}{|c|l|}
\hline Coarse aggregate physical property & \multicolumn{1}{|c|}{ Relative range } \\
\hline \multirow{2}{*}{ Shape } & $\begin{array}{l}\text { Flat/Elongated: } 0.01-0.03 \\
\text { Bulky: } 0.007-0.03 \\
\text { Rounded: }<0.007\end{array}$ \\
\hline Angularity & $\begin{array}{l}\text { Angular: } 0.0015-0.0095 \\
\text { Subangular: }<0.0015\end{array}$ \\
\hline \multirow{2}{*}{ Surface texture } & Rough: $0.007-0.011$ \\
& Moderate: $0.00015-0.0085$ \\
& Smooth: $<0.00015$ \\
\hline
\end{tabular}


Table $4 \mathrm{~b}$. Coarse aggregate physical properties values multiplied by $\mathbf{1 0 , 0 0 0}$

\begin{tabular}{|c|l|}
\hline Coarse aggregate physical property & \multicolumn{1}{|c|}{ Relative range } \\
\hline \multirow{2}{*}{ Shape } & Flat/Elongated: $100-300$ \\
& Bulky: $70-300$ \\
& Rounded: $<70$ \\
\hline Angularity & Angular: $15-95$ \\
& Subangular: $<15$ \\
\hline \multirow{3}{*}{ Surface texture } & Rough: $70-110$ \\
& Moderate: $1.5-85$ \\
& Smooth: $<1.5$ \\
\hline
\end{tabular}

\section{Merits and Limitations of Test Method and Imaging System}

The micro computer with built-in camera has proven to be very efficient in assessing the coarse aggregate profiles and associated characteristics. Using the Matlab-based program and a certain picture resolution, the system is optimally calibrated for analyzing particles greater than $4.75 \mathrm{~mm}$. But, as common to most of the video imaging based systems, this system also has its limitations when dealing with the aggregate particles. These limitations (disadvantages), together with its merits (advantages), are presented in Table 5 below.

Table 5. Advantages and disadvantages of the coarse aggregate evaluation method and system

\begin{tabular}{|c|c|c|}
\hline System \& Method & Advantages & Disadvantages \\
\hline $\begin{array}{l}\text { Sony Vaio UX280P } \\
\text { Fourier morphological } \\
\text { analysis method }\end{array}$ & $\begin{array}{l}\text { Very fast acquisition \& analysis of the } \\
\text { aggregate picture (under } 20 \mathrm{sec} \text { ) } \\
\text { Portable and easy to handle, very good for } \\
\text { field evaluations } \\
\text { Very good evaluation of the aggregate } \\
\text { profile characteristics } \\
\text { User friendly interface }\end{array}$ & $\begin{array}{l}\text { Single aggregate particle analysis } \\
\text { Analyzes only the boundary surface } \\
\text { texture (not entire photographed } \\
\text { surface) } \\
\text { Longer analysis time for resolutions } \\
\text { higher than } 640 \times 480\end{array}$ \\
\hline
\end{tabular}

\section{CONCLUSIONS}

For many years, it has been understood that aggregate physical properties (e.g., shape, angularity, and surface texture) affect the performance of unbound granular layers and surface courses of both asphalt and hydraulic cement concrete. Currently, image analysis procedures to determine the coarse aggregate physical properties are being considered as very useful and viable alternatives over the more labor-intensive and time consuming manual test procedures. This study focused on developing a portable image analysis technique for measuring the coarse aggregate physical properties.

This objective was achieved through the use of a pocket computer with a built-in camera and a Matlab computer program. The computer program developed for this study is a good practical implementation of Fourier analysis method (Masad and Button 2000; Wettimuny and 
Penumadu 2004; Wang et al. 2005) to quantify the shape, angularity, and surface texture of aggregates. The developed methodology is not tied to a specific device but is transferable to other integrated computer-camera devices or to systems incorporating individual computer (with Matlab) and camera components.

Based on the acquired analysis results the following conclusions can be drawn:

- The developed portable image analysis system can successfully be used for field evaluation of coarse aggregate.

- The image processing using Fourier morphological analysis can accurately quantify the shape, angularity, and surface texture indices of coarse aggregate from the outlines of particles. Threshold factors can easily be incorporated in Matlab software for image analysis.

- Statistical analysis of the results obtained indicate that Fourier method of image processing and analysis can quantitatively rank coarse aggregates consistently with their qualitative ranking. Statistical test results show that that profile parameters are aggregate-source sensitive.

- This image analysis method is not affected by aggregate color, as different backgrounds can be used to provide adequate contrast to acquire suitable images.

- Threshold factor depends on the brightness of the aggregate picture but does not influence the final values of the aggregate profile. In order to get reliable results, aggregate pictures should be taken from a close range ( 2 to 4 in) rather than a longer (6 to $10 \mathrm{in}$ ) range.

- Statistically stable values for shape, angularity, and surface texture factors can be evaluated on 15 profiles of any orientation.

\section{RECOMMENDATIONS}

1. VDOT's Materials Division should institute a program to characterize the morphology of coarse aggregates using the portable image analysis system. This could most efficiently be accomplished by having district materials personnel image particles during routine sampling at sources or collecting samples of aggregate for imaging at a central facility. The sampling should be performed on a regular basis (e.g., monthly or quarterly) on aggregates being supplied for specific applications. The image processing and analysis should be performed either by the laboratory in VDOT's Materials Division or by VTRC. Matlab is available on a networked desktop at VTRC.

2. VDOT's Materials Division or VTRC should collect the characterization data on aggregate sources and build a database. This database would facilitate the determination of source 
variability and is a key element in ultimately tying aggregate morphology to performance in the various applications.

3. VTRC and VDOT'S Materials Division should institute a new research project to examine the relationship between aggregate morphologic characteristics and performance in HMA and base materials. The goal of this research should be to develop the concepts that apply aggregate morphologic characterization to pavement engineering to make the best use of available materials.

\section{COSTS AND BENEFITS ASSESSMENT}

The primary product of this project has been the development of a portable image analysis system for characterizing coarse aggregate morphology, a key element of which is the processing and analysis code for use with Matlab 6.5. The system can be put into immediate use with equipment on hand: VTRC has a networked desktop with Matlab and digital cameras; and the Materials Division central and district offices should have digital cameras available. Aspects of implementation include the following, which are expected to total less than $\$ 25,000$ :

- Additional cameras, if needed, could be purchased for an estimated $\$ 250$ each.

- Training of personnel to acquire images and complete processing and analysis could be accomplished with a $1 / 2$-day workshop for 15 to 20 individuals (est. \$7,500).

- An additional 15 to 30 minutes per source would be needed during routine sampling to acquire samples for transport or images of particles (est. \$7,500).

- A total of 200 person-hours/yr would be needed to build and maintain the database (est. \$6,000).

This project is the initial step in a multiphase program that envisions the application of aggregate morphologic characteristics into the engineering of paving materials. The ultimate benefits of such application will be realized on completion of future work. At this early stage, realistic estimates of anticipated monetary benefits are subject to enormous uncertainty and thus cannot be provided. However, such monetary benefits should be significant since volumetrically, aggregates constitute by far the largest component of paving materials and so even small efficiencies in their use can result in substantial savings. The anticipated benefits would be realized through increased knowledge about the morphologic characteristics of the aggregates being used, developing an understanding of how these characteristics impact and affect performance of aggregate materials, and how the information can be put to use in engineering practice. Specific areas where benefits might accrue are:

- Better management of aggregate resources should maximize the use of locally available materials, which reduces transportation costs, a major and increasing factor in aggregate pricing and reduces environmental impacts 
- Improved engineering of aggregate paving materials should enable construction of longer-lived, higher capacity pavements with reduced binder (asphalt or hydraulic cement) contents.

\section{ACKNOWLEDGMENTS}

Research staff at VTTI in cooperation with VTRC's Materials Group conducted this project. The authors acknowledge the assistance and direction from the technical review panel, Larry Lundy, David Lee, and Richard Meininger; and the suggestions and comments from Audrey Moruza and James Gillespie on the Cost and Benefit section.

\section{REFERENCES}

Al-Rousan, T., E. Masad, L. Myers, and C. Spiegelman (2005). New Methodology for Shape Classification of Aggregates. In Transportation Research Record 1913. Transportation Research Board, Washington, DC, pp. 11-23.

Al-Rousan, T., E. Masad, E. Tutumluer, and T. Pan (2006). Evaluation of Image Analysis Techniques for Quantifying Aggregate Shape Characteristics. Elsevier, Construction and Building Materials, Vol. 21, pp. 978-990.

Atkins, N. H. (2003). Highway Materials, Soils, and Concretes. Prentice Hall, Upper Saddle River, NJ, pp. 121-142.

Fletcher, T., C. Chandan, E. Masad, and K. Sivakumar (2002). Measurement of Aggregate Texture and its Influence on Hot Mix Asphalt Permanent Deformation. Journal of Testing and Evaluation, Vol. 30, No. 6, pp. 1-8.

Hossain, M.S., F. Parker, and P.S. Kandhal (2000). Comparison and Evaluation of Tests for Coarse Aggregate Particle Shape, Angularity, and Surface Texture. Journal of Testing and Evaluation, Vol. 28, No. 2, pp. 77-87.

Lanaro, F. and P. Tolppanen (2002). 3D Characterization of Coarse Aggregates. Elsevier, Engineering Geology, Vol. 15, pp. 17-30.

Masad, E., and J.W. Button (2000). Unified Imaging Approach for Measuring Aggregate Angularity and Texture. Computer-Aided Civil and Infrastructure Engineering, Vol. 15, pp. 273-280.

Masad, E., T. Al-Rousan, J.W. Button, D. Little, and E. Tutumluer (2007a). Test Methods for Characterizing Aggregate Shape, Texture, and Angularity. NCHRP Report 555.

Transportation Research Board, Washington, DC. 
Masad, E., T. Al-Rousan, M. Bathina, J. McGahan, and C. Spiegelman (2007b). Analysis of Aggregate Shape Characteristics and Its Relationship to HMA Performance. Road Materials and Pavement Design, Vol. 8, No. 2, pp. 317-350.

The Mathworks, Inc. (2004). MATLAB: The Language of Technical Computing. The Mathworks, Natick, MA.

Pan, T. and E. Tutumluer (2006). Quantification of Coarse Aggregate Surface Texture Using Image Analysis. Journal of Testing and Evaluation, Vol. 35, No. 2, pp. 1-10.

Rao, C., E. Tutumluer, and J.A. Stefanski (2001). Coarse Aggregate Shape and Size Properties Using a New Image Analyzer. Journal of Testing and Evaluation, Vol. 29, No. 5, pp. 461471.

Umbaugh, S.E. (2005). Computer Imaging: Digital Imaging Analysis and Processing. CRC Press, Taylor \& Francis Group, Boca Raton, FL.

Wang, L., X. Wang, L. Mohammad, and C. Abadie (2005). Unified Method to Quantify Aggregate Shape Angularity and Texture Using Fourier Analysis. Journal of Materials in Civil Engineering, Vol.17, No. 5, pp. 498-504.

Wang, L., J. S. Lai, and J.D. Frost (1997). Fourier morphological descriptors of aggregate profiles. Second International Conference on Image Technology Applications in Civil Engineering, pp. 76-85.

Wettimuny, R., and D. Penumadu (2004). Application of Fourier Analysis to Digital Imaging for Particle Shape Analysis. Journal of Computing in Civil Engineering, Vol. 18, No. 1, pp. 2-9. 
APPENDIX A

COARSE AGGREGATE IMAGE ANALYSIS PROFILES AND PHYSICAL PROPERTIES VALUES

\begin{tabular}{|c|c|c|c|c|c|}
\hline \multicolumn{6}{|c|}{ Piney River-Aplite, Granite } \\
\hline $\begin{array}{c}\text { Particle } \\
\text { No. }\end{array}$ & Aggregate Picture & Aggregate Edge & Alpha S & Alpha R & Alpha T \\
\hline $\begin{array}{l}1 \\
\text { Th }=0.2 \\
\text { (threshold) }\end{array}$ & & & 0.021 & 0.000067 & 0.000068 \\
\hline $\begin{array}{l}2 \\
\mathrm{Th}=0.1\end{array}$ & & & 0.0086 & 0.00021 & 0.00064 \\
\hline $\begin{array}{l}3 \\
\mathrm{Th}=0.1\end{array}$ & & & 0.0038 & 0.00015 & 0.00028 \\
\hline $\begin{array}{l}4 \\
\mathrm{Th}=0.12\end{array}$ & & & 0.025 & 0.00032 & 0.00051 \\
\hline $\begin{array}{l}5 \\
\mathrm{Th}=0.1\end{array}$ & & & 0.0042 & 0.00027 & 0.00078 \\
\hline
\end{tabular}




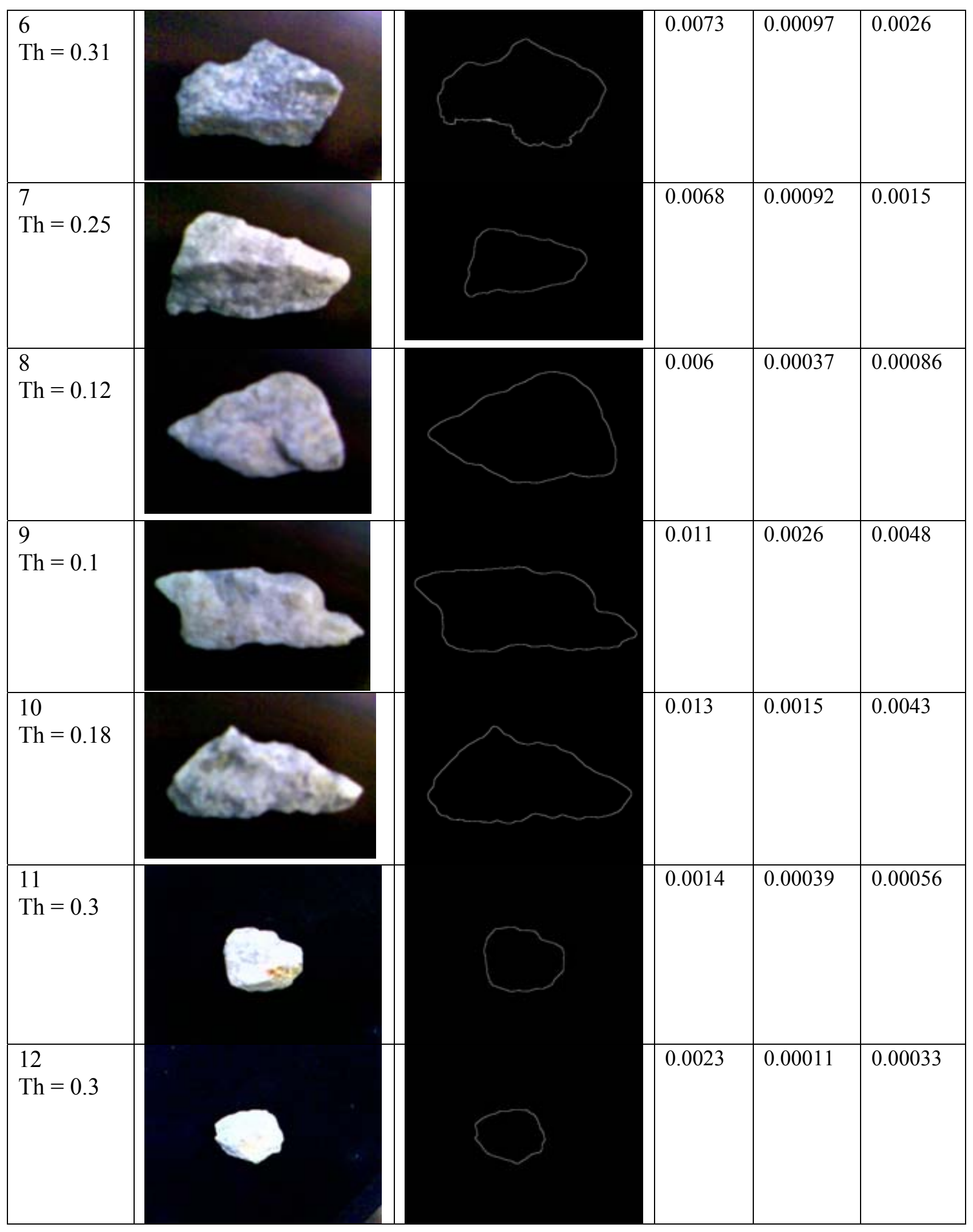




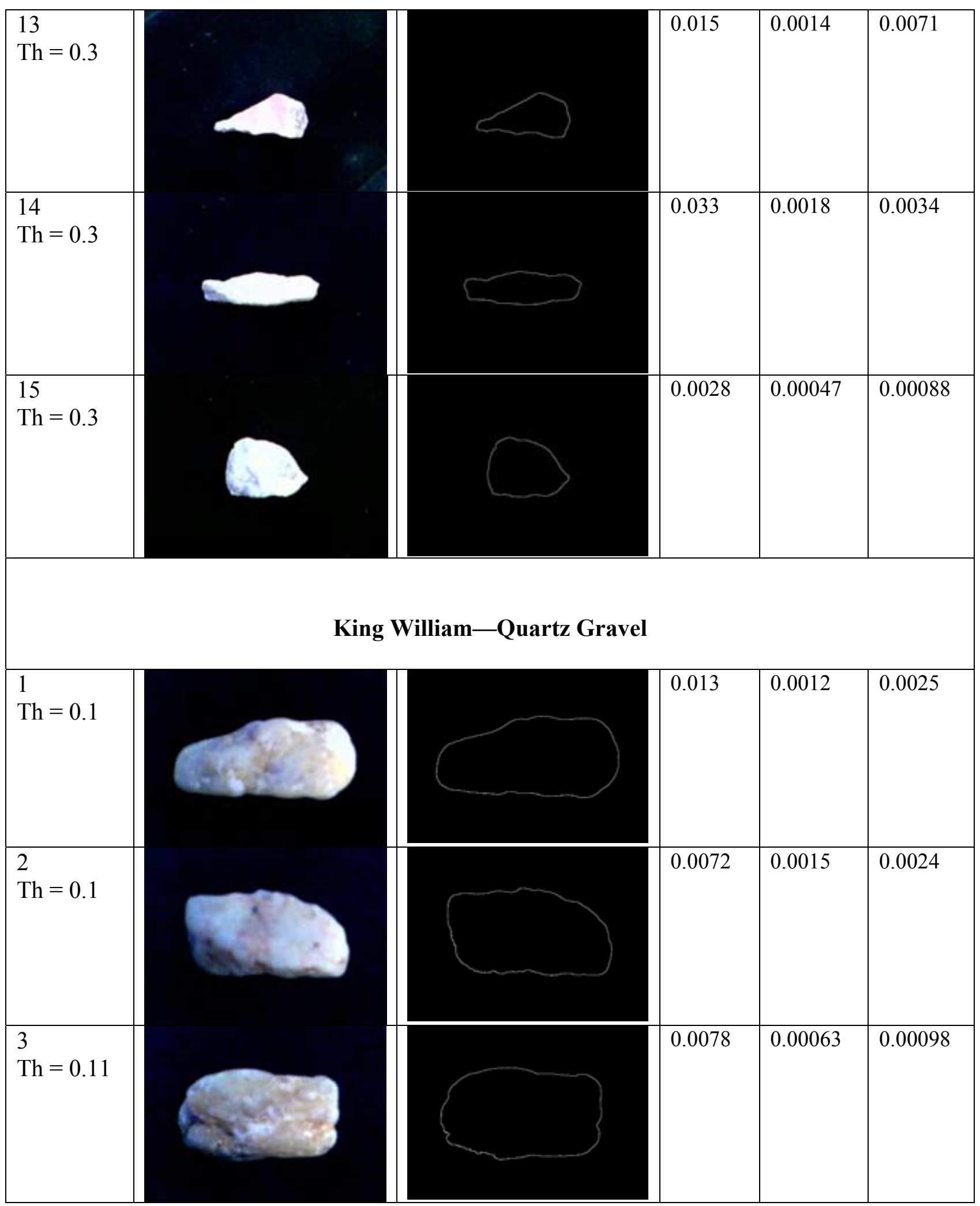




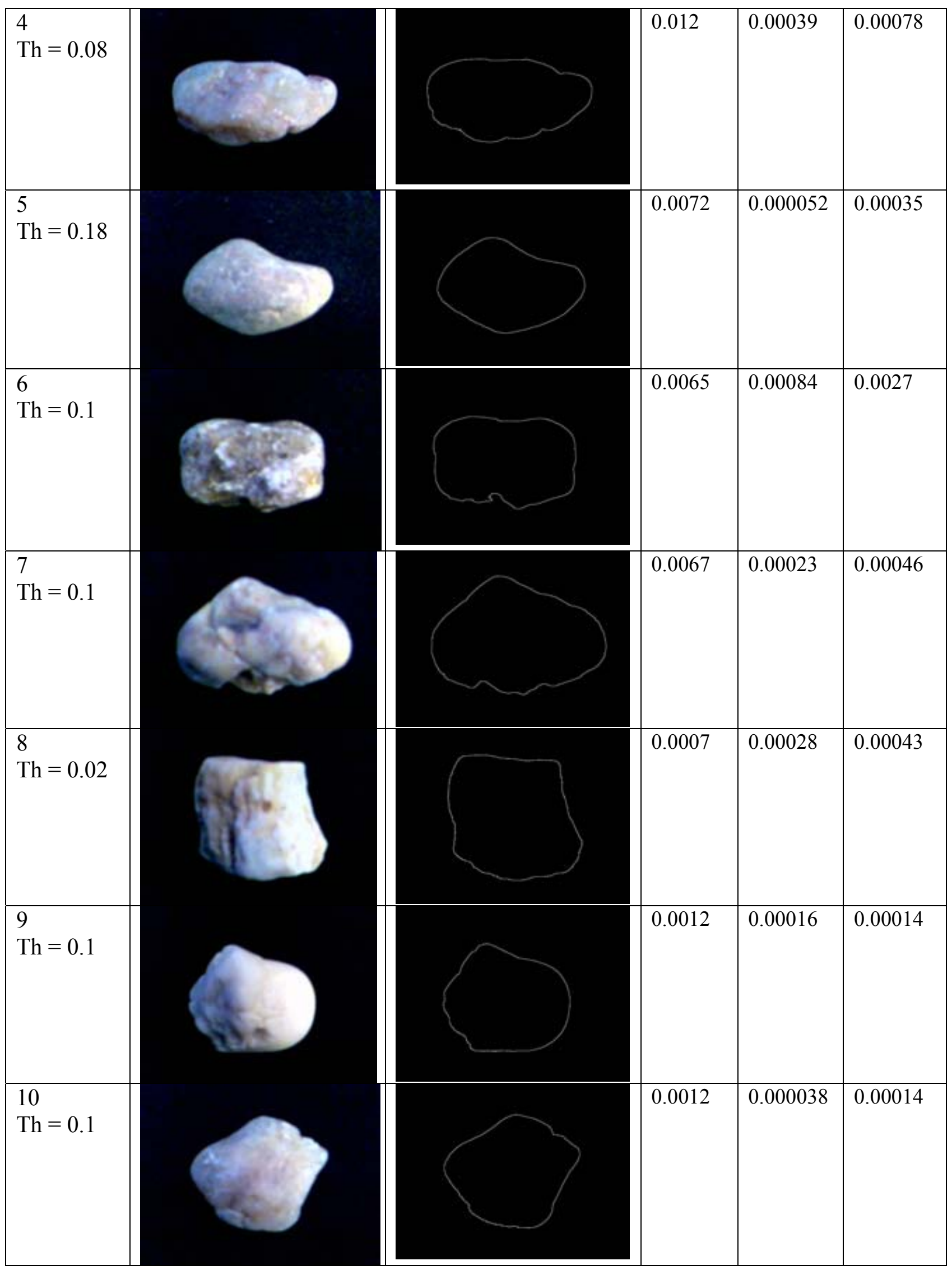




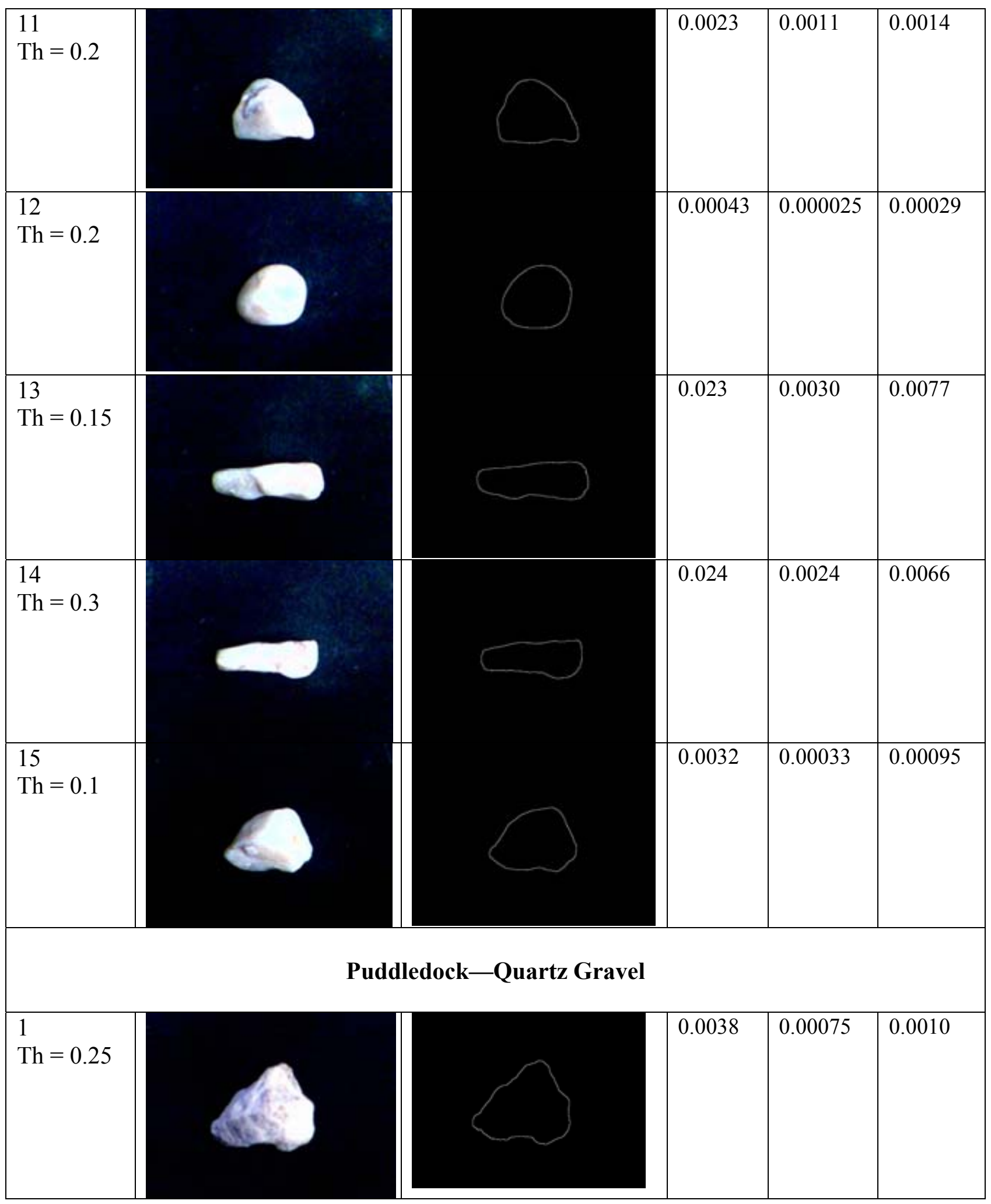




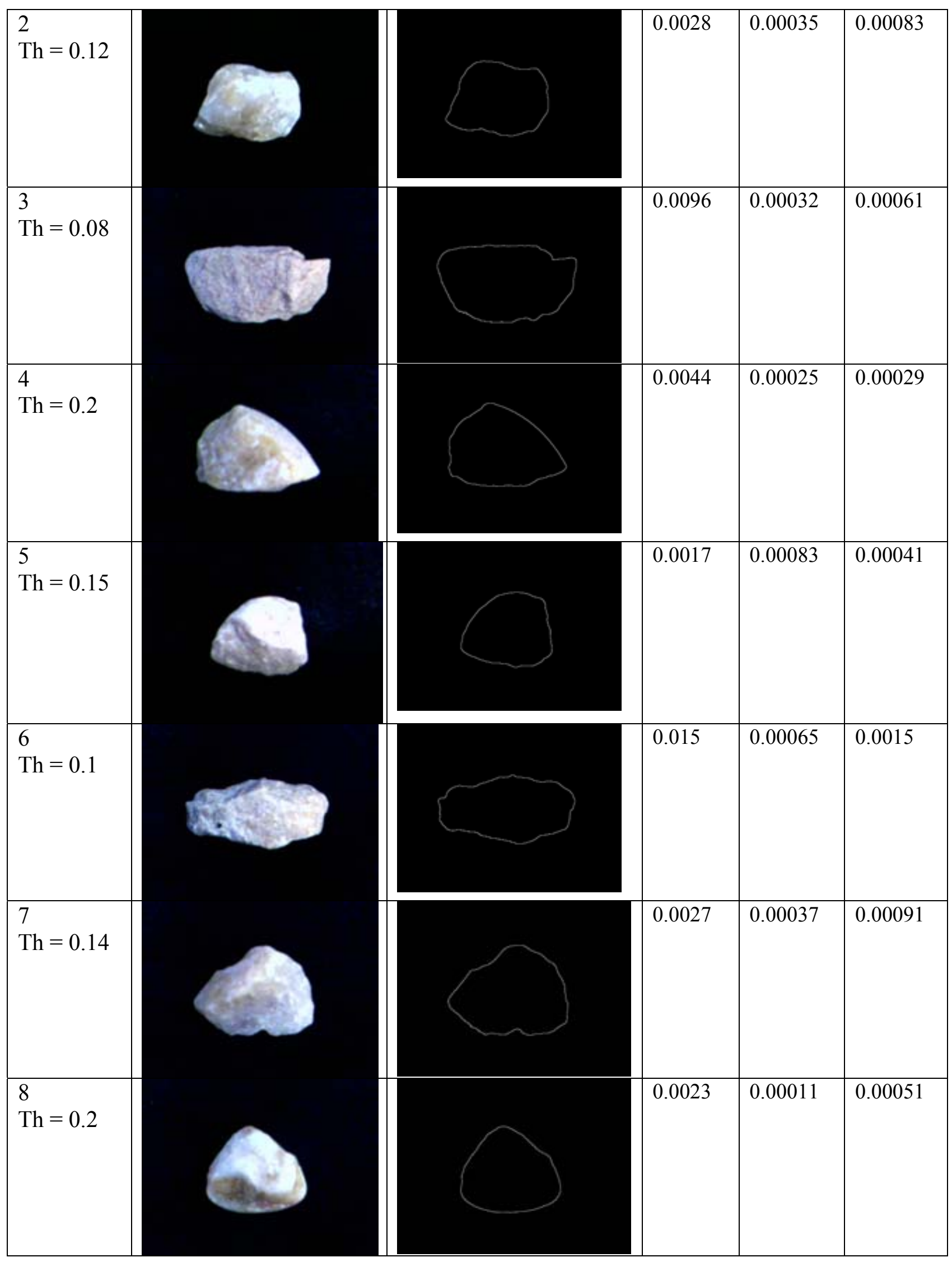




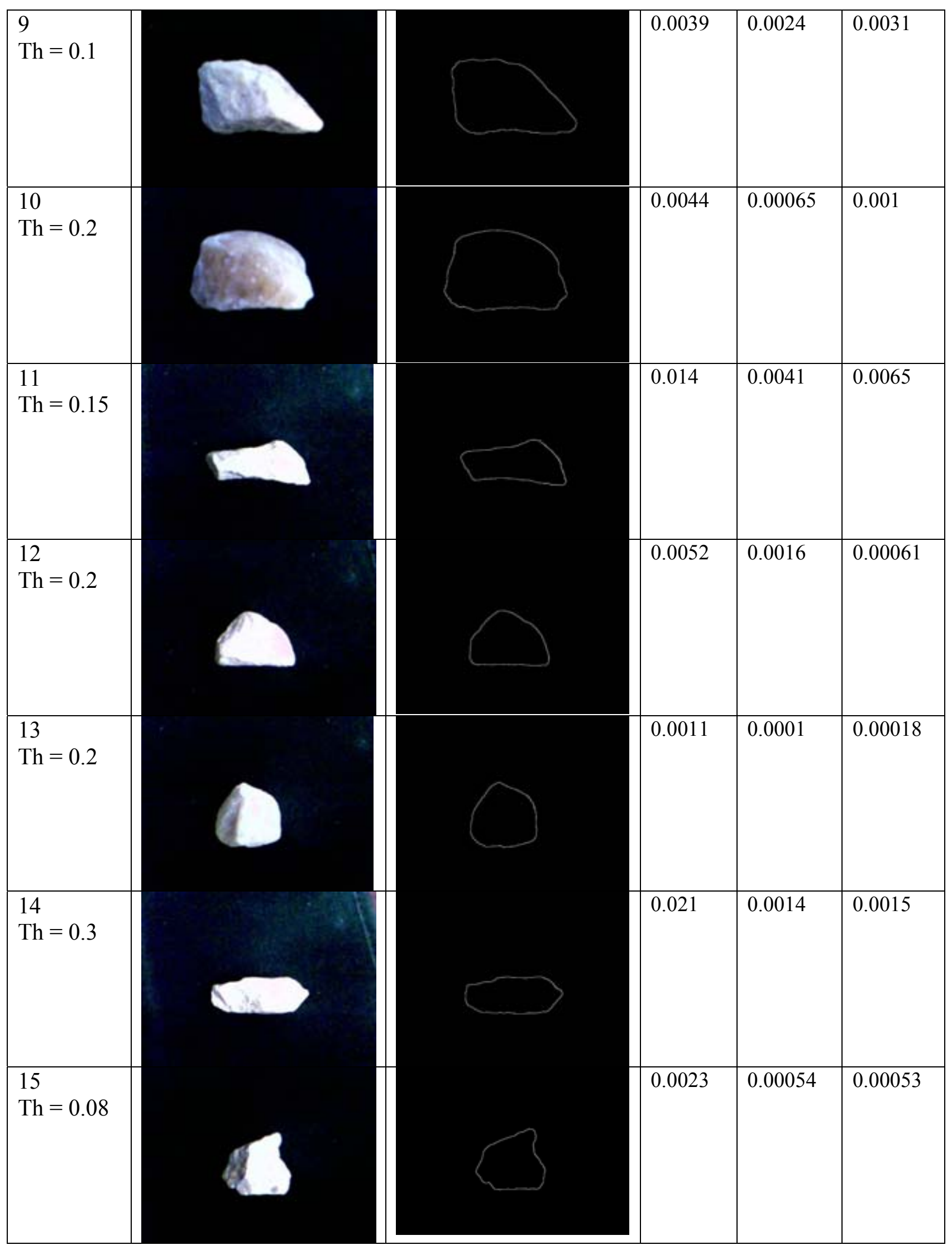




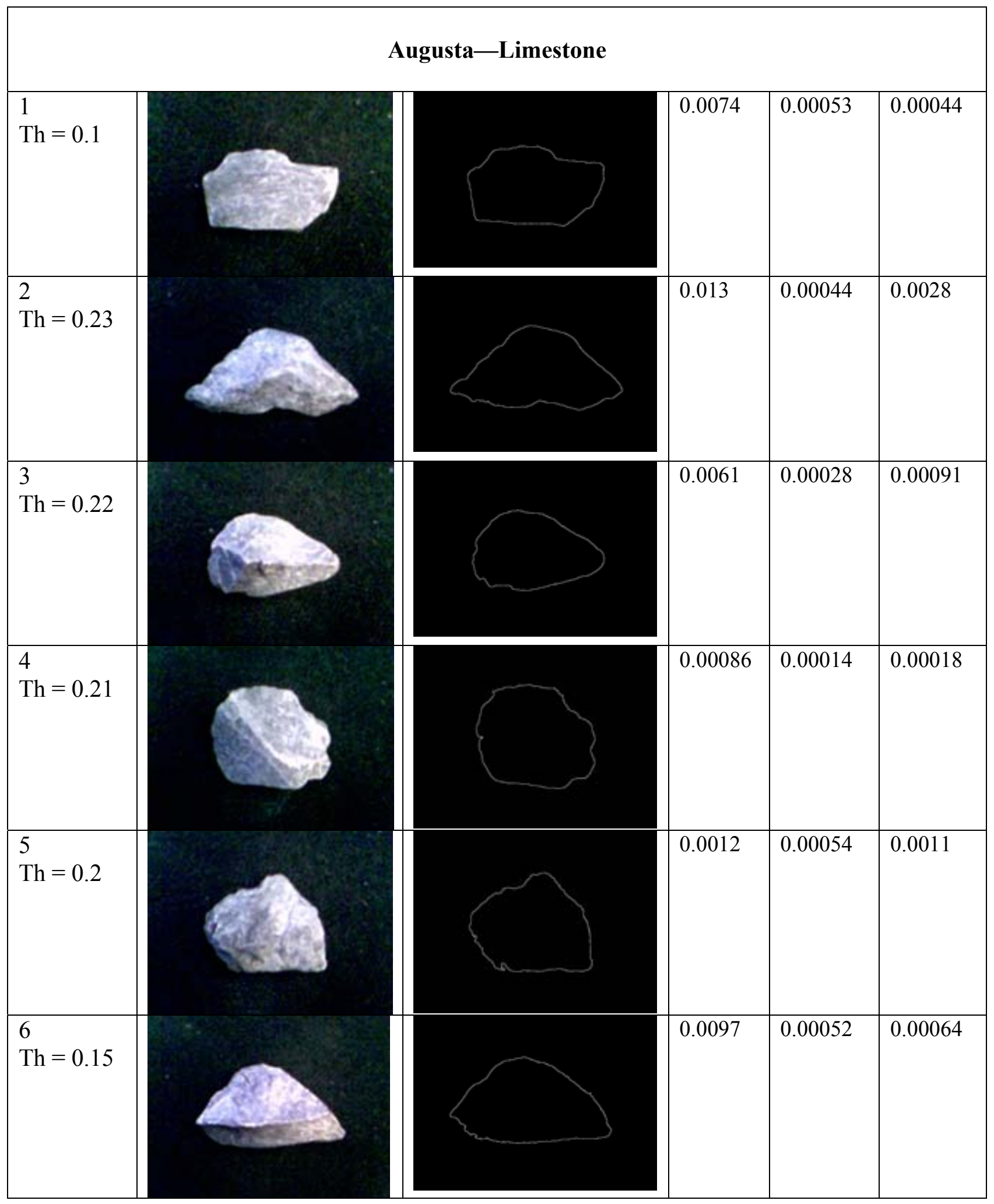




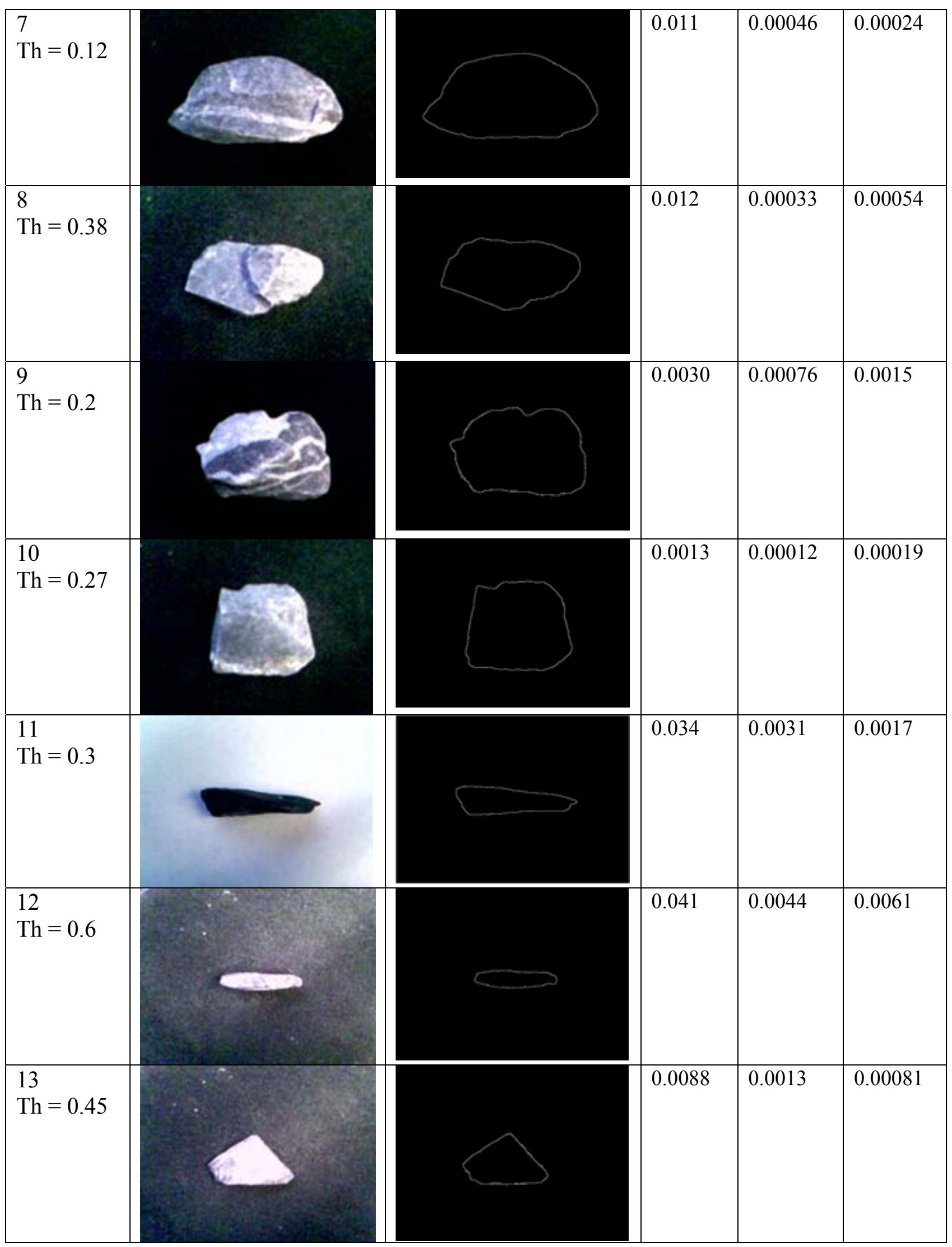




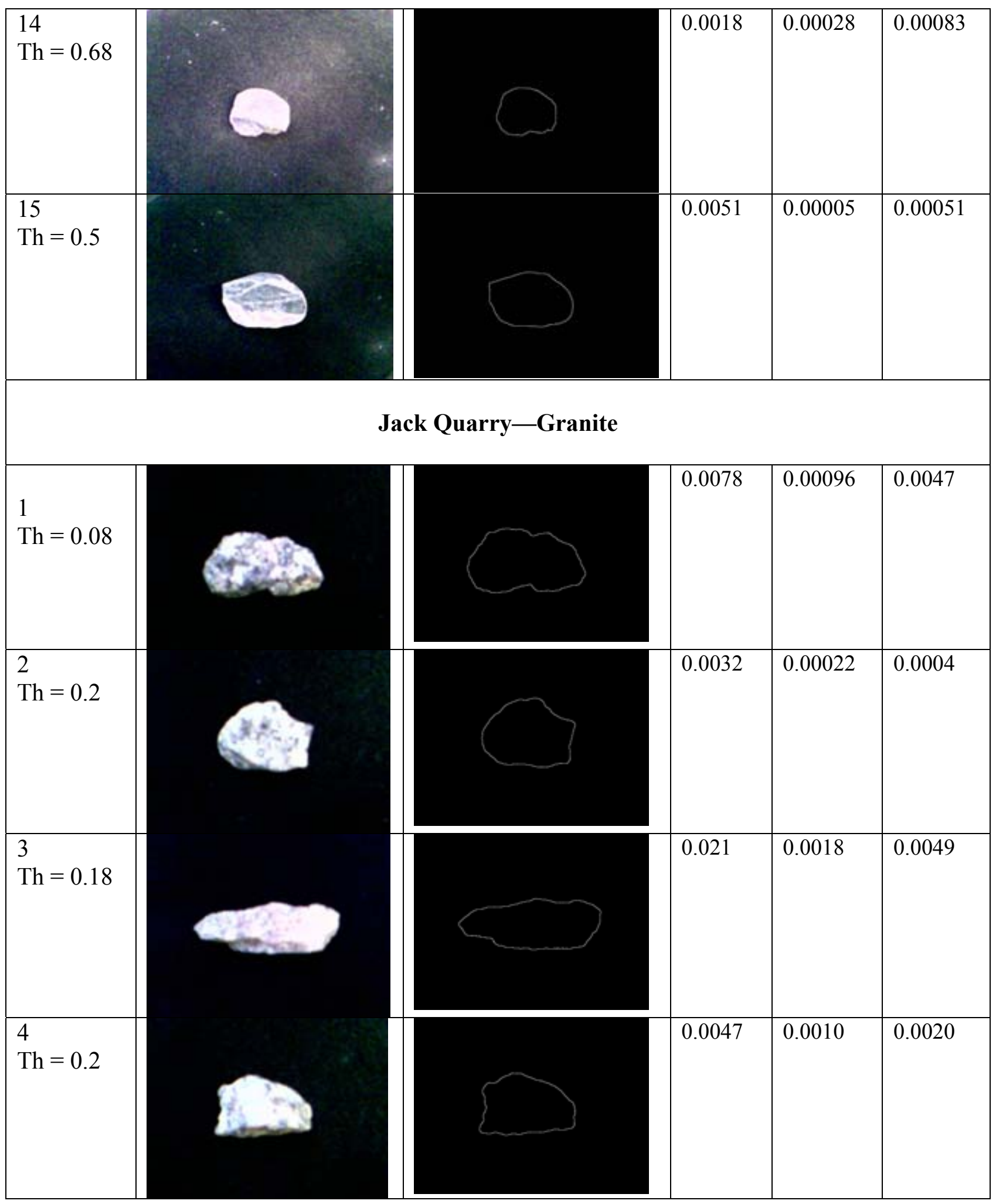




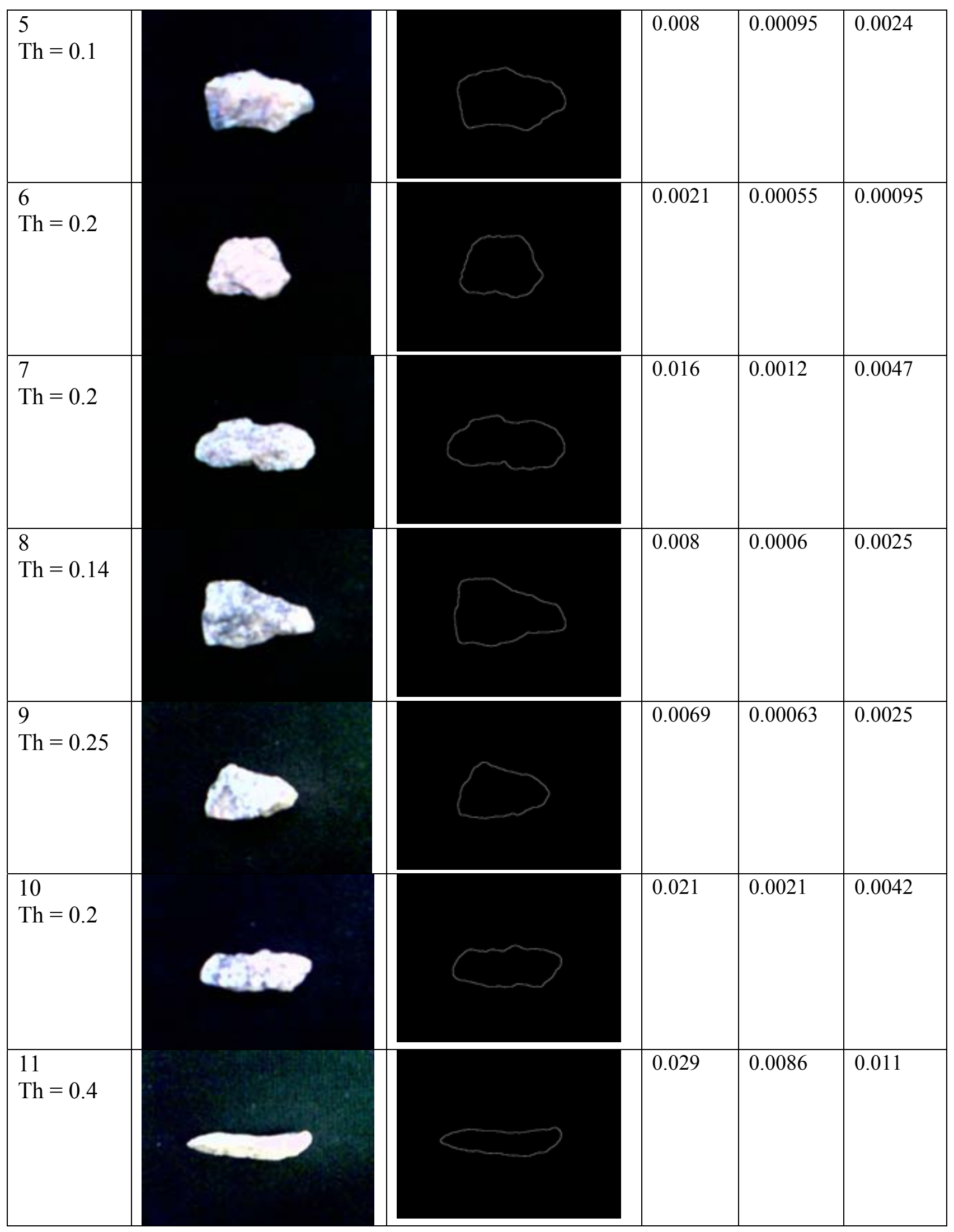




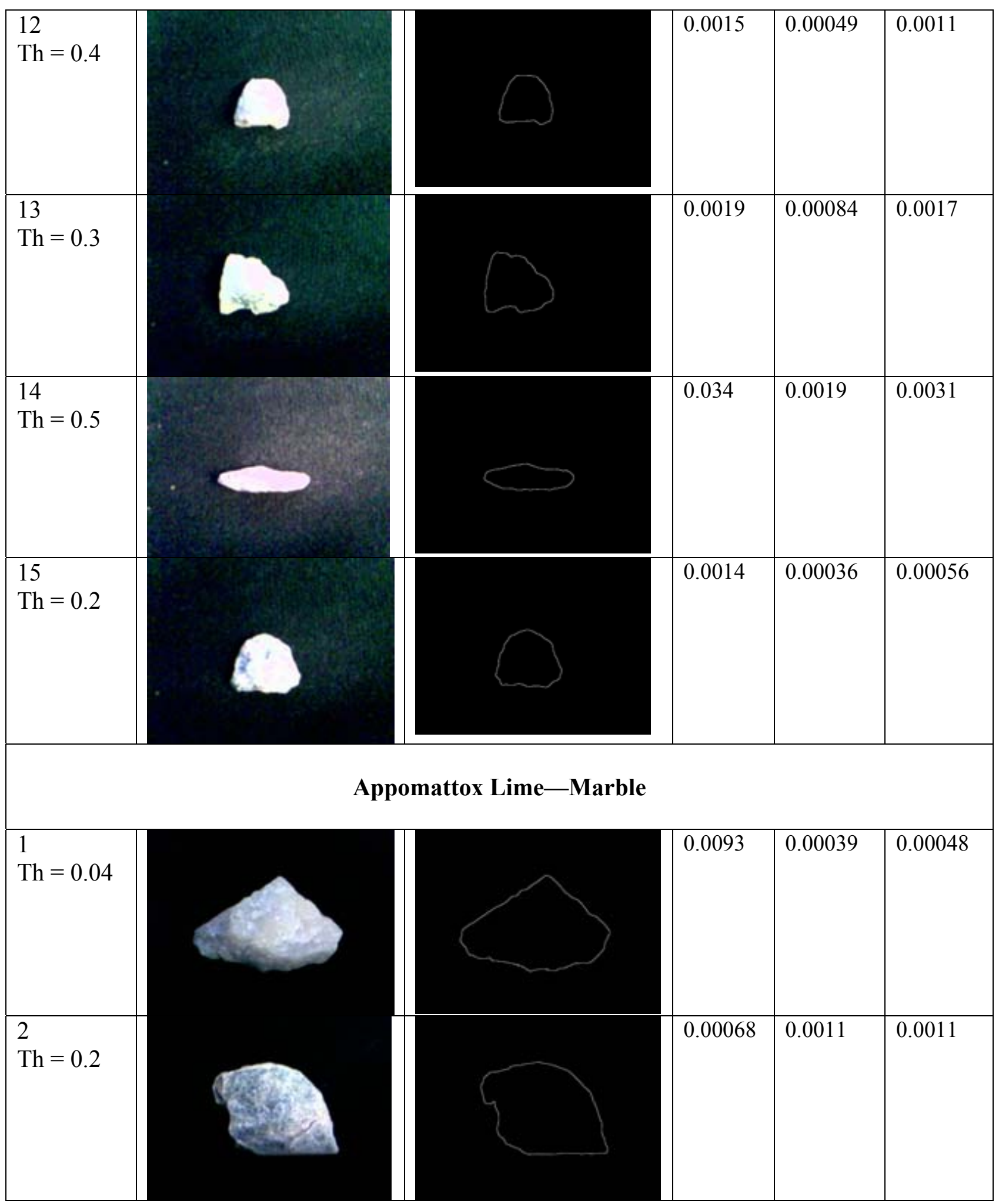




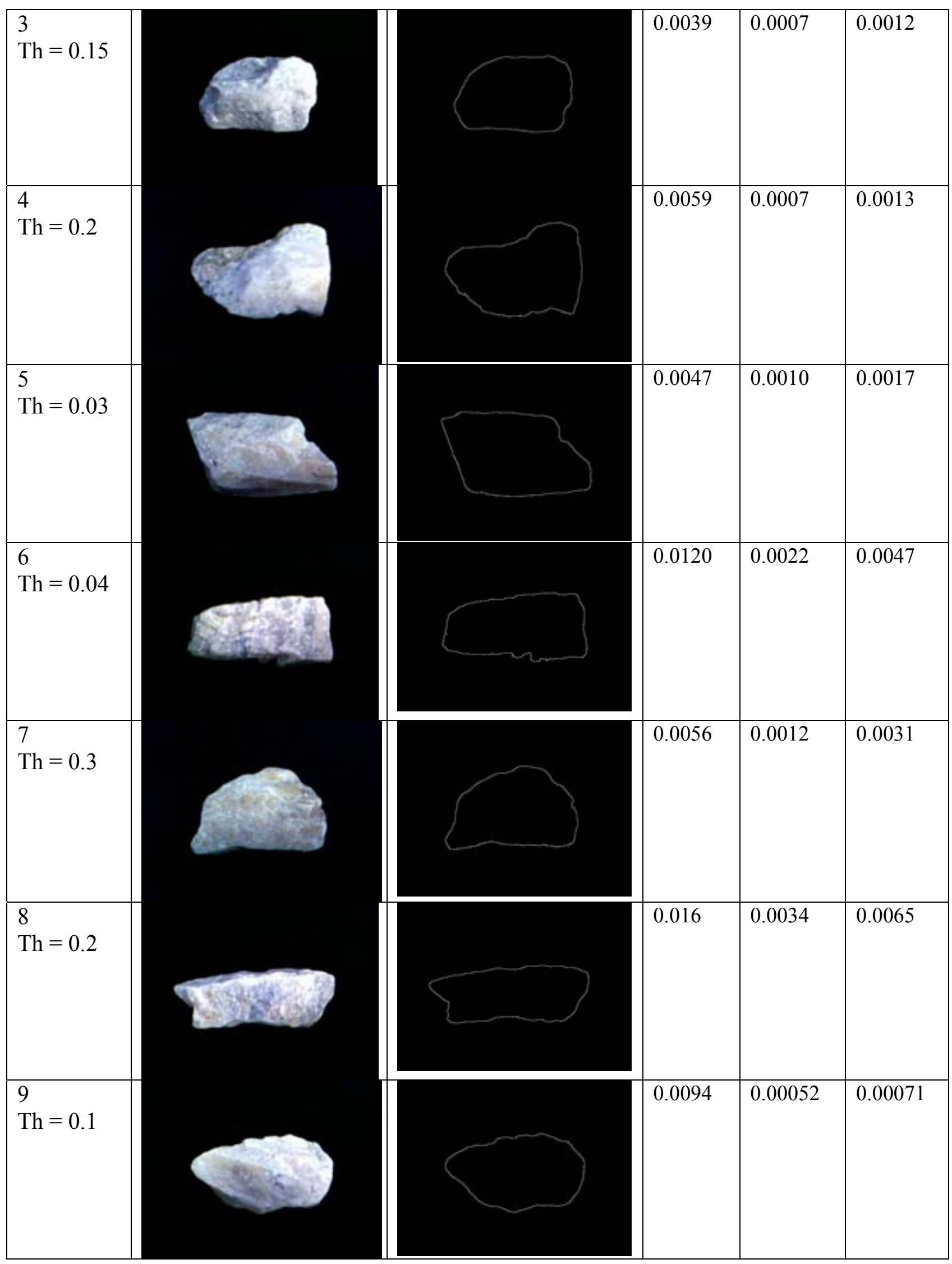




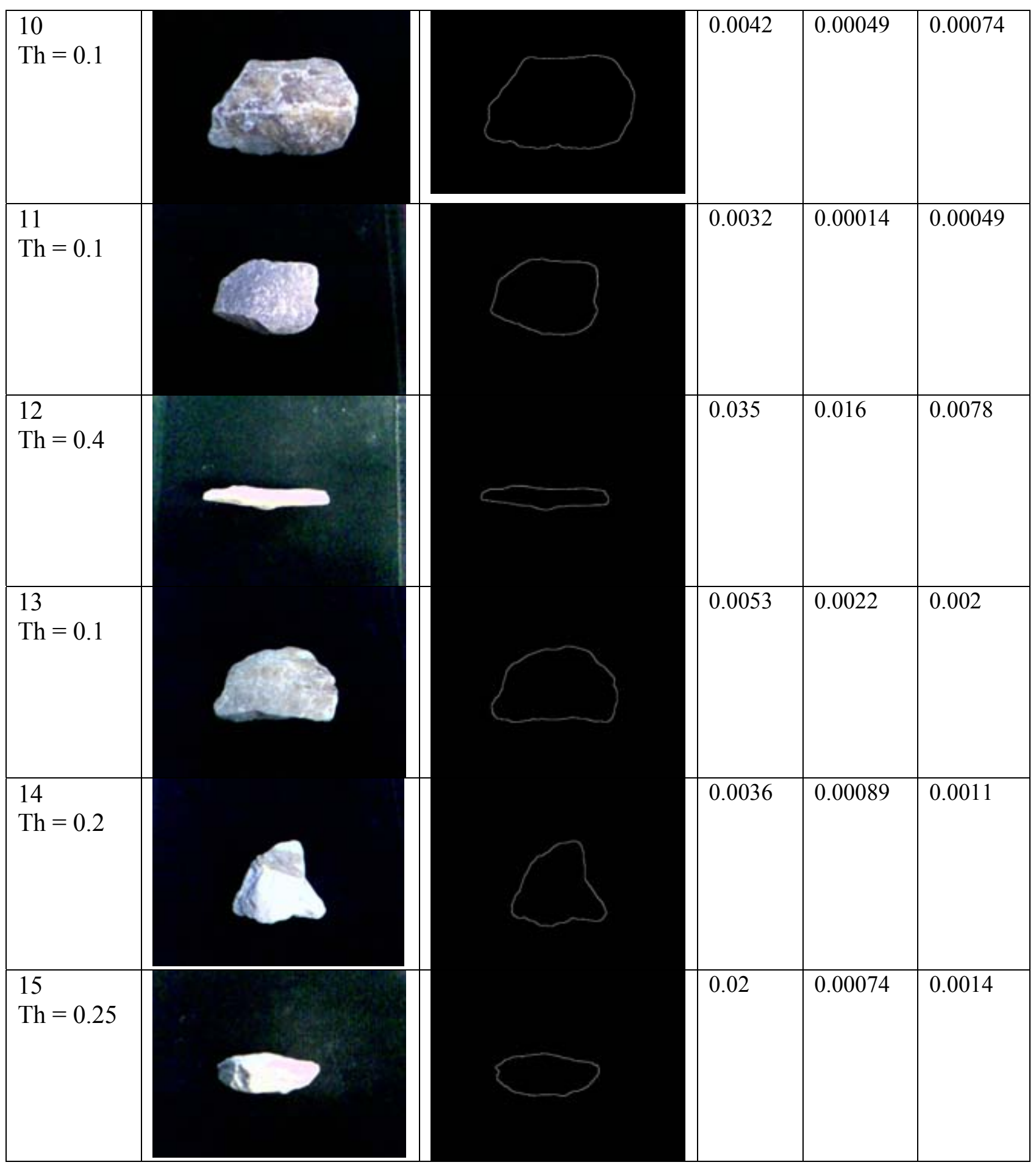




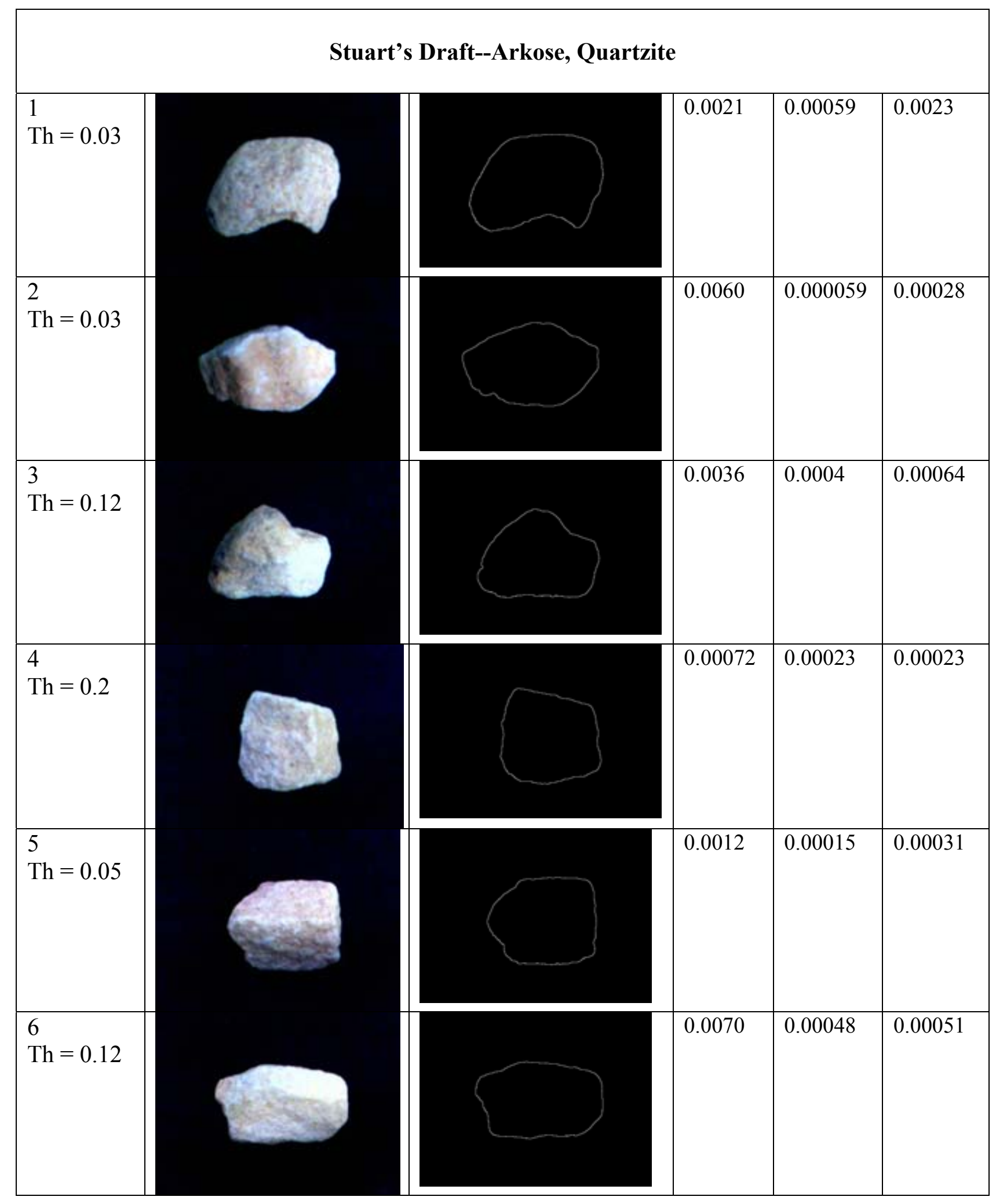




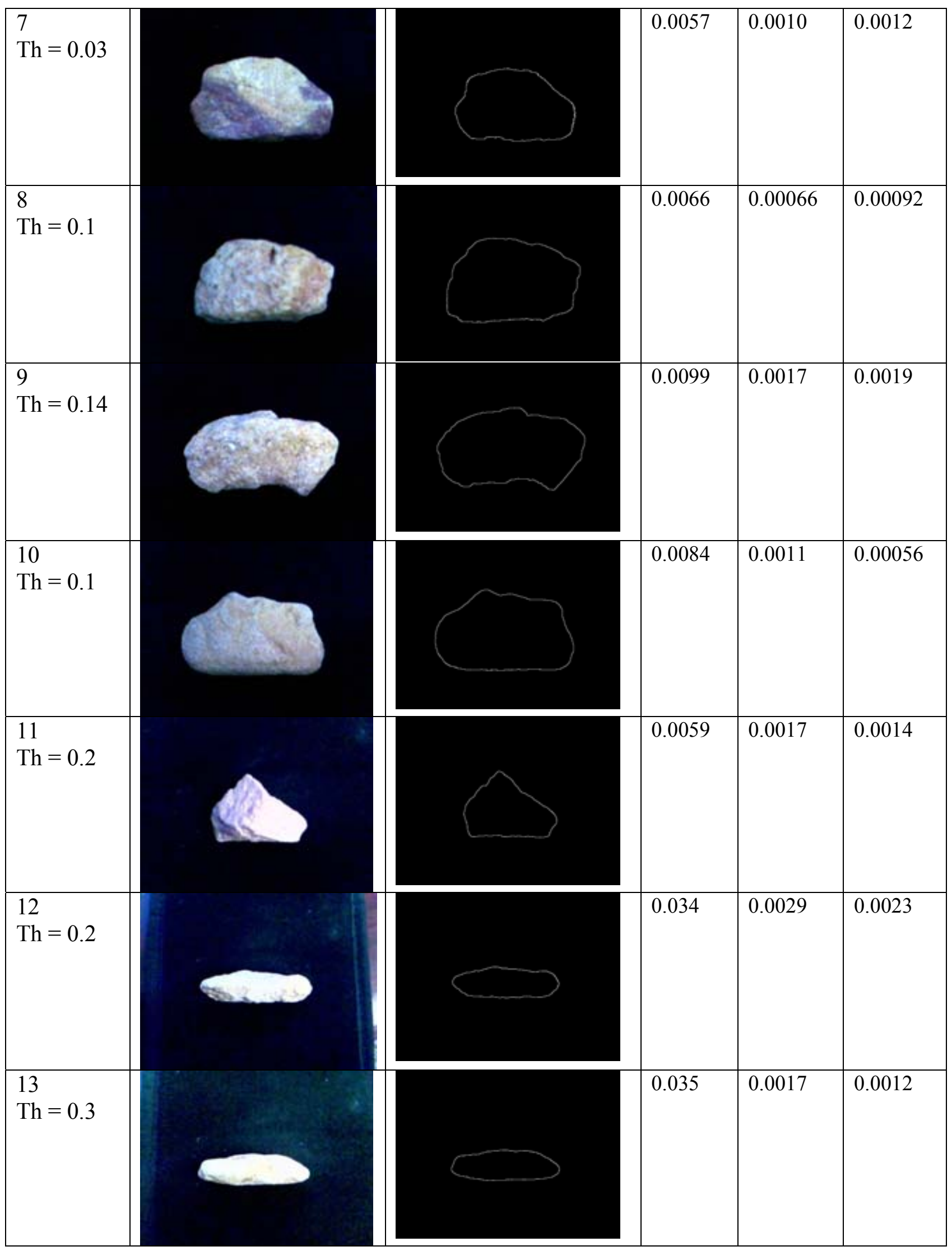




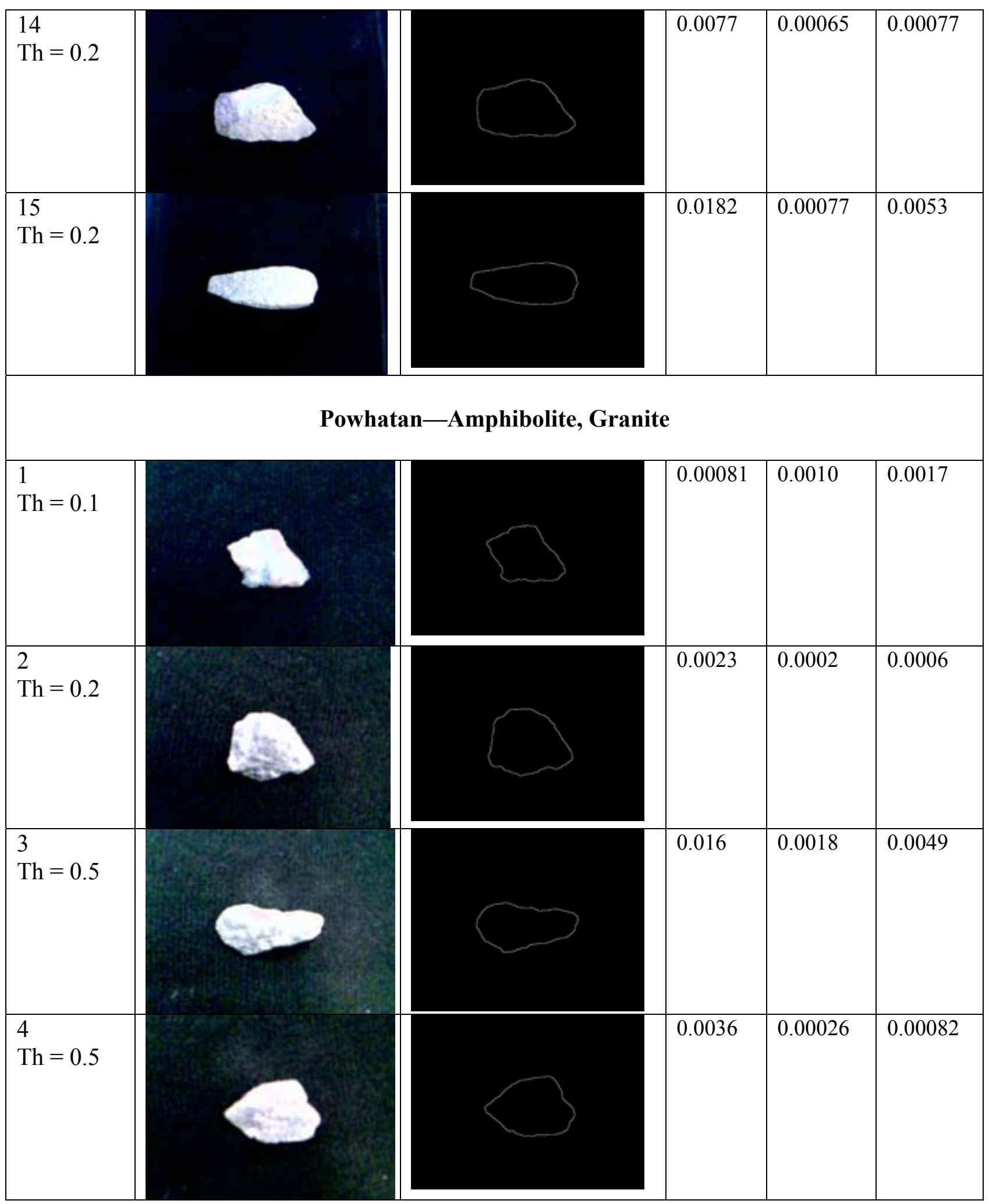




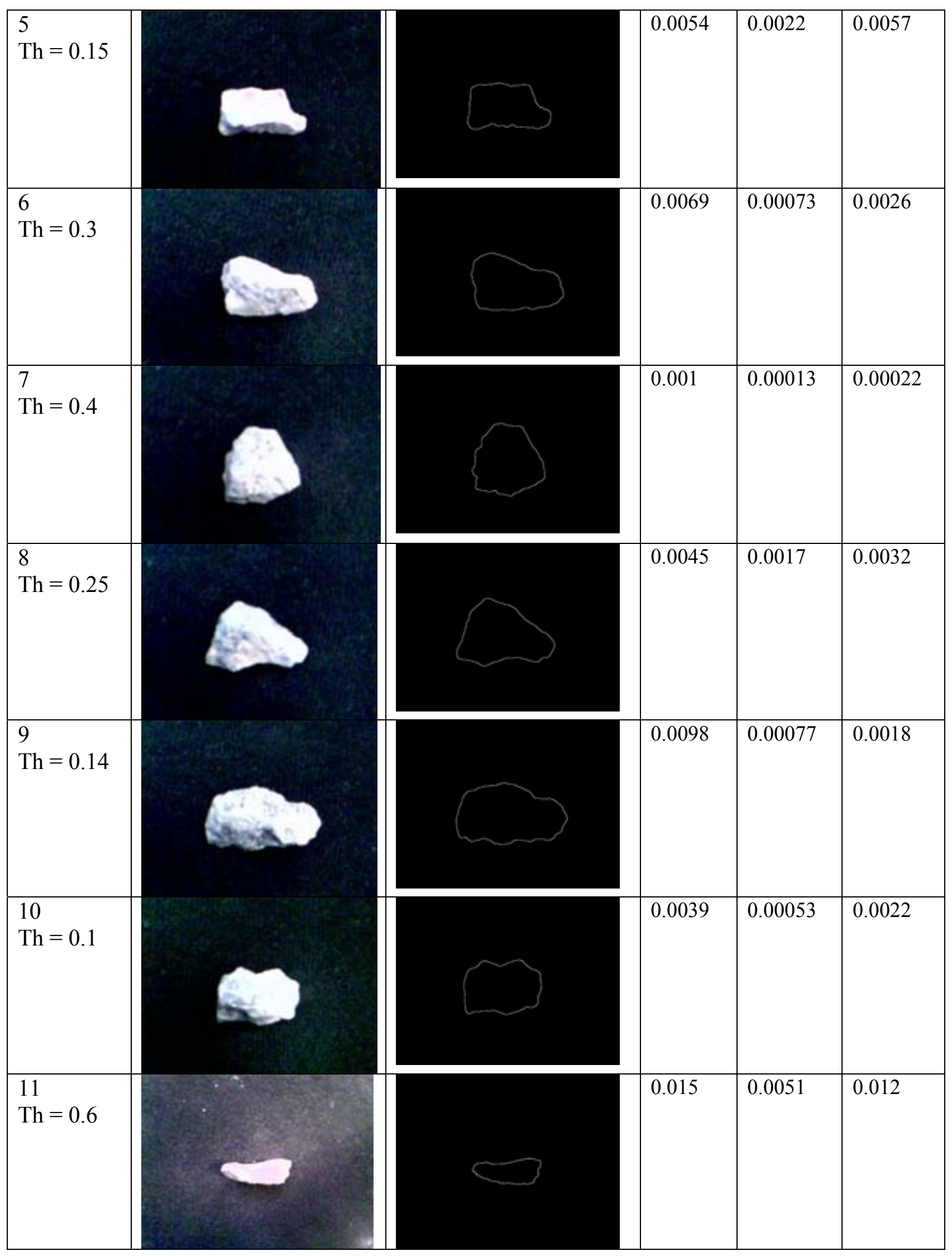




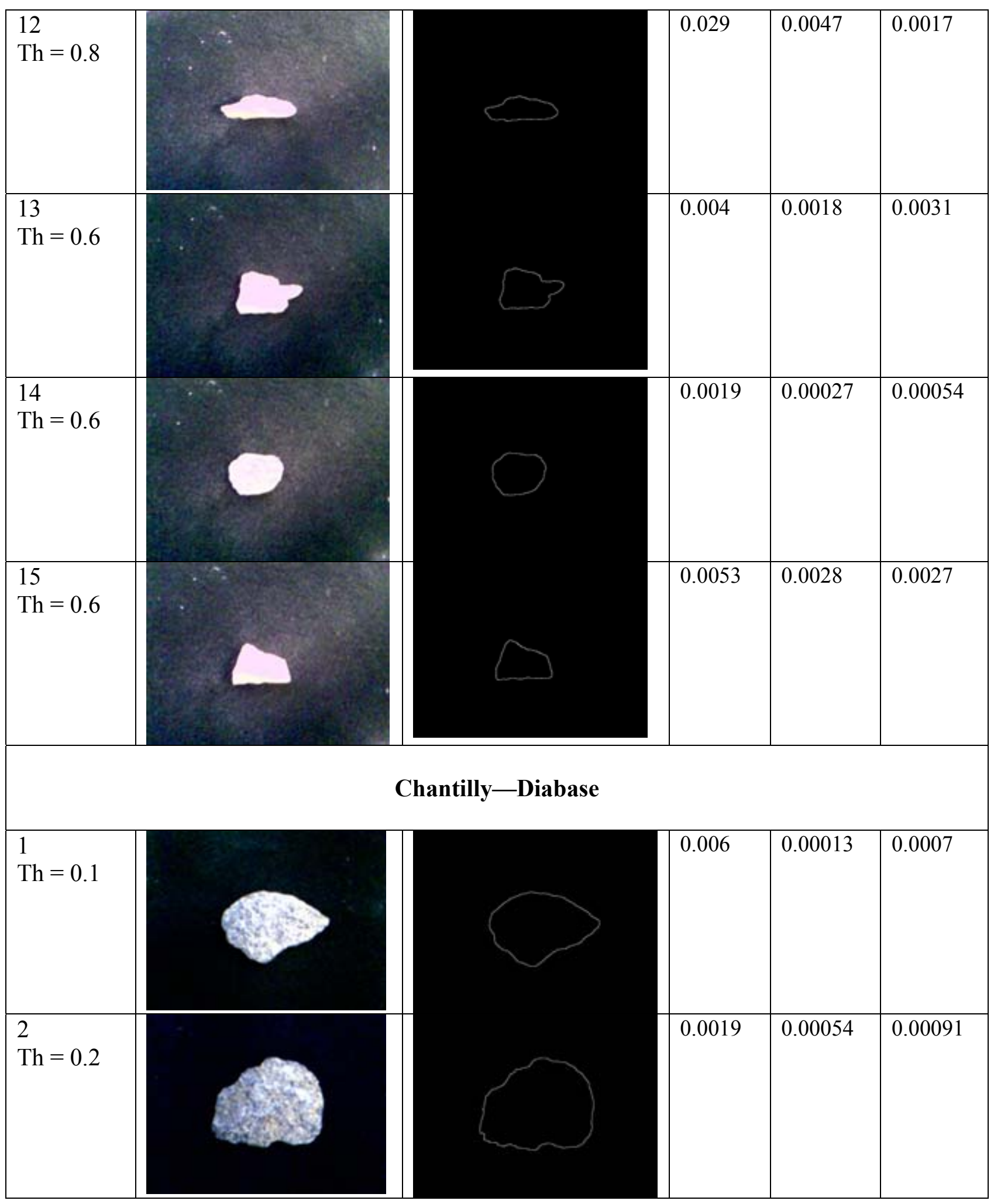




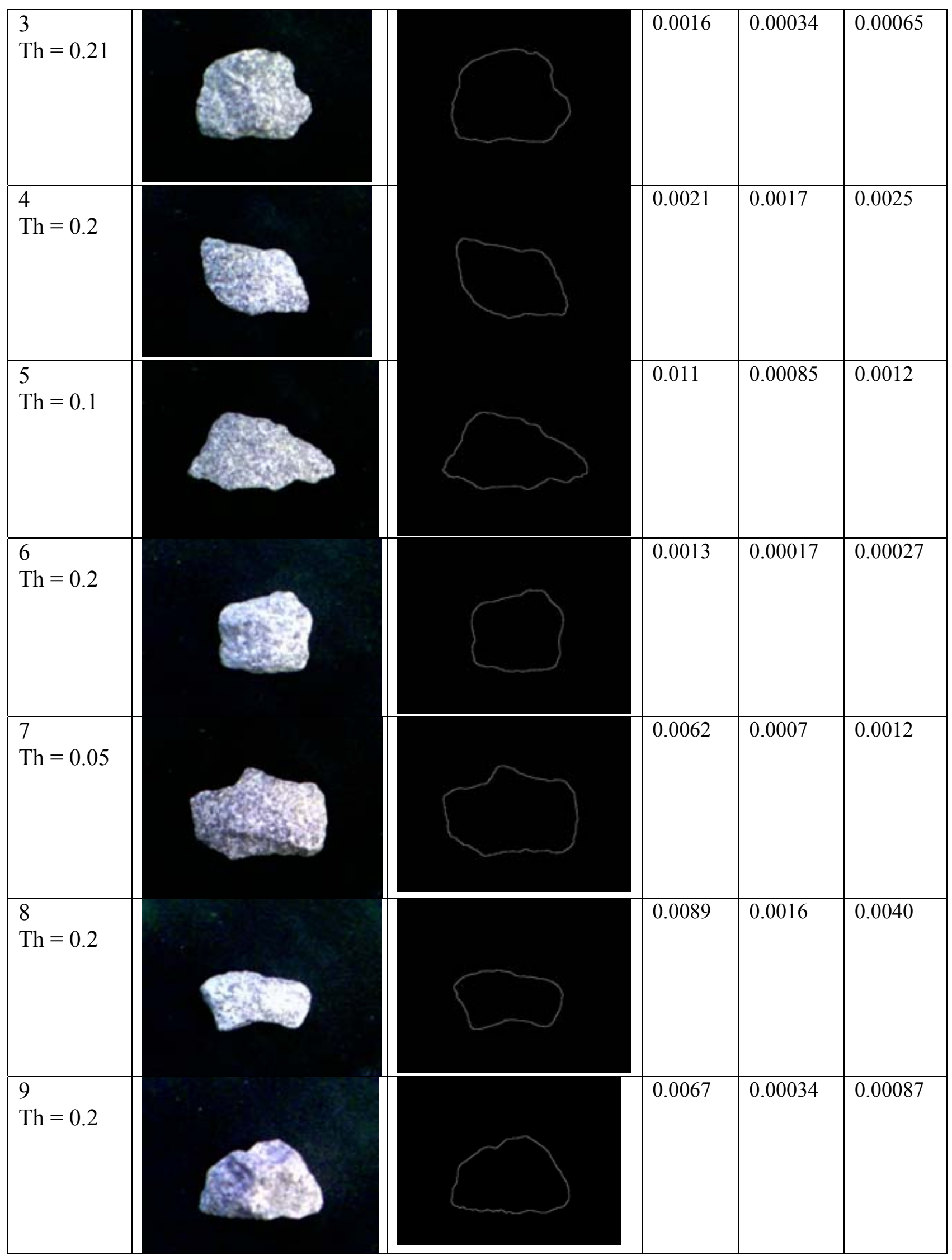




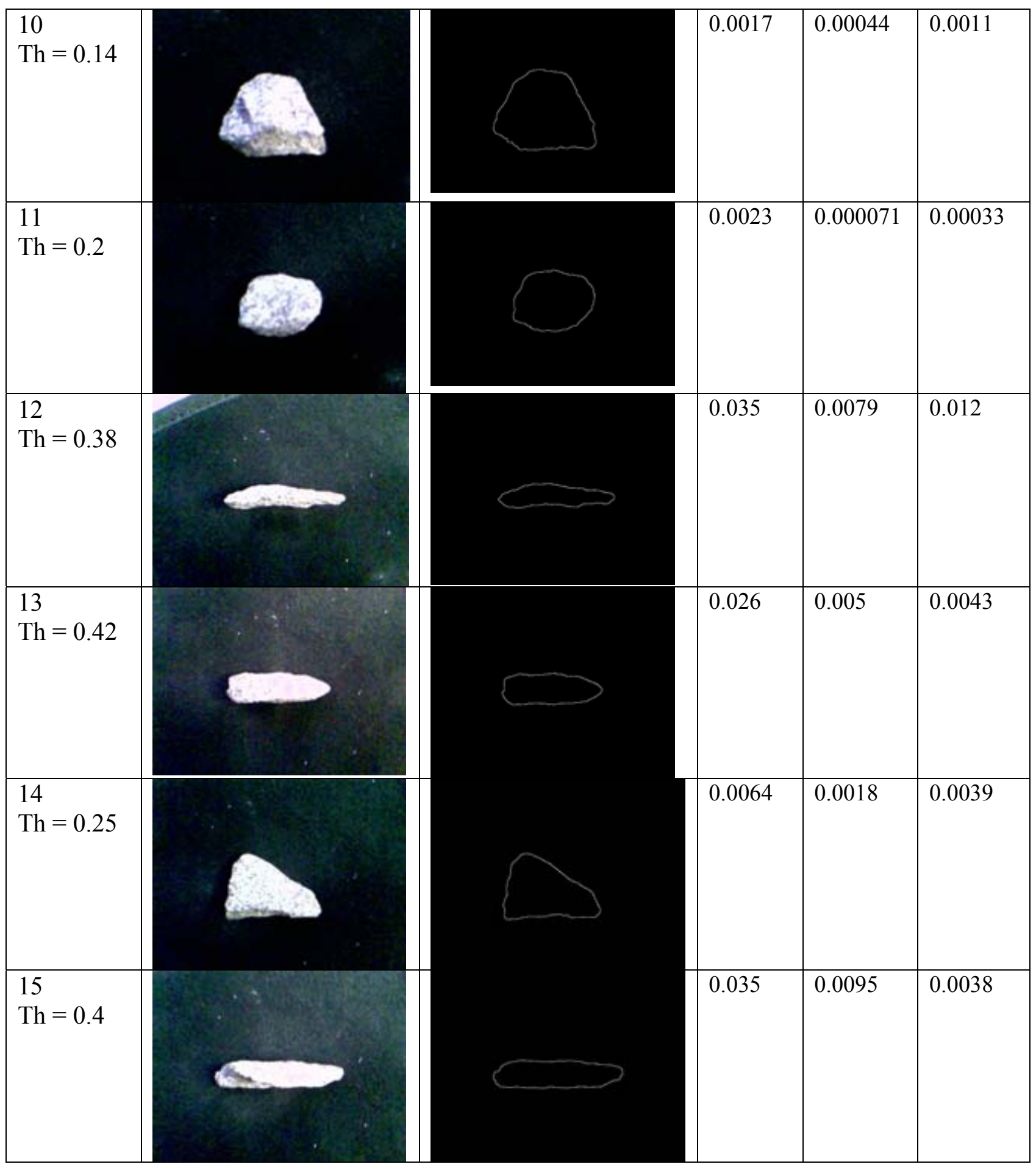




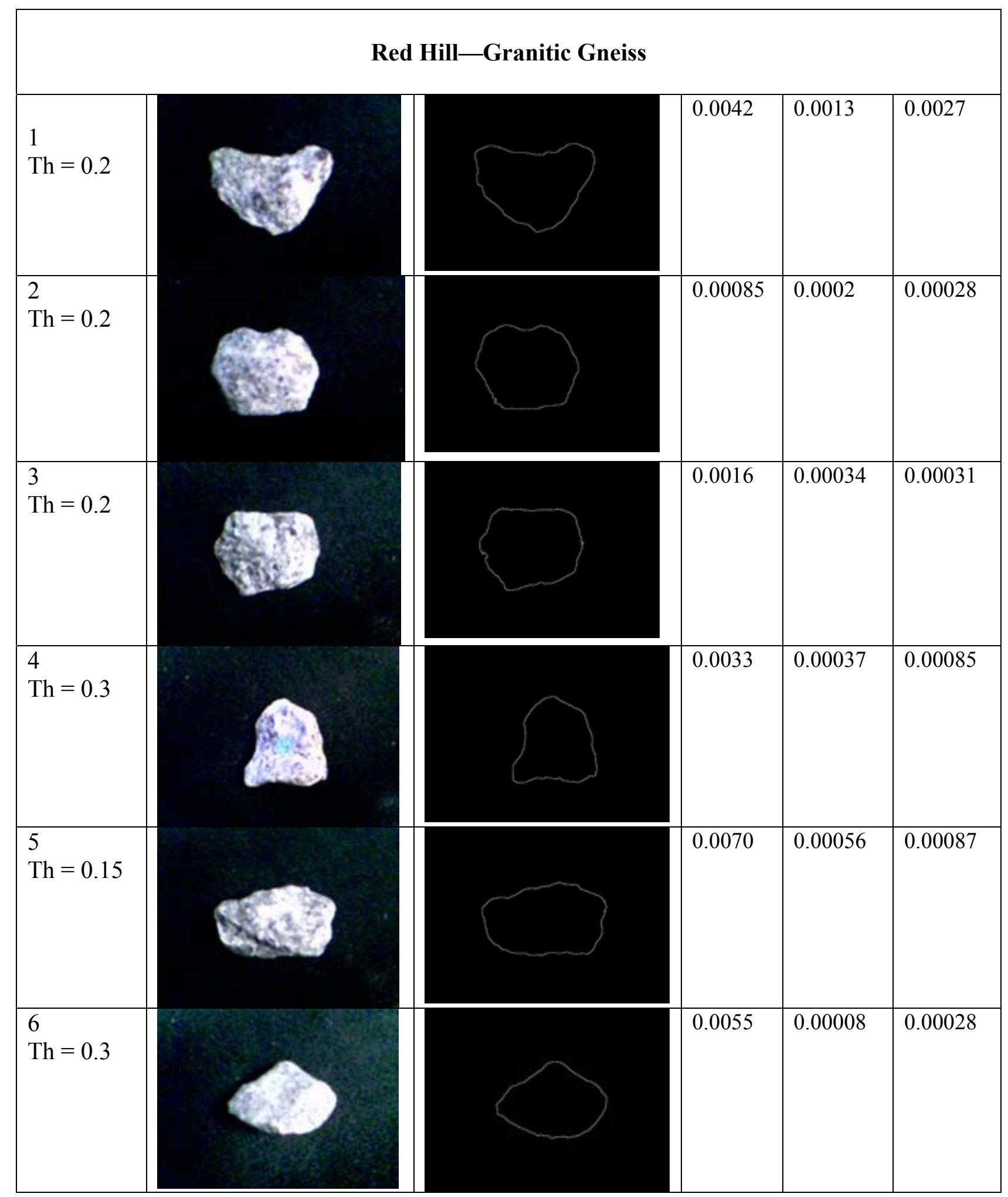




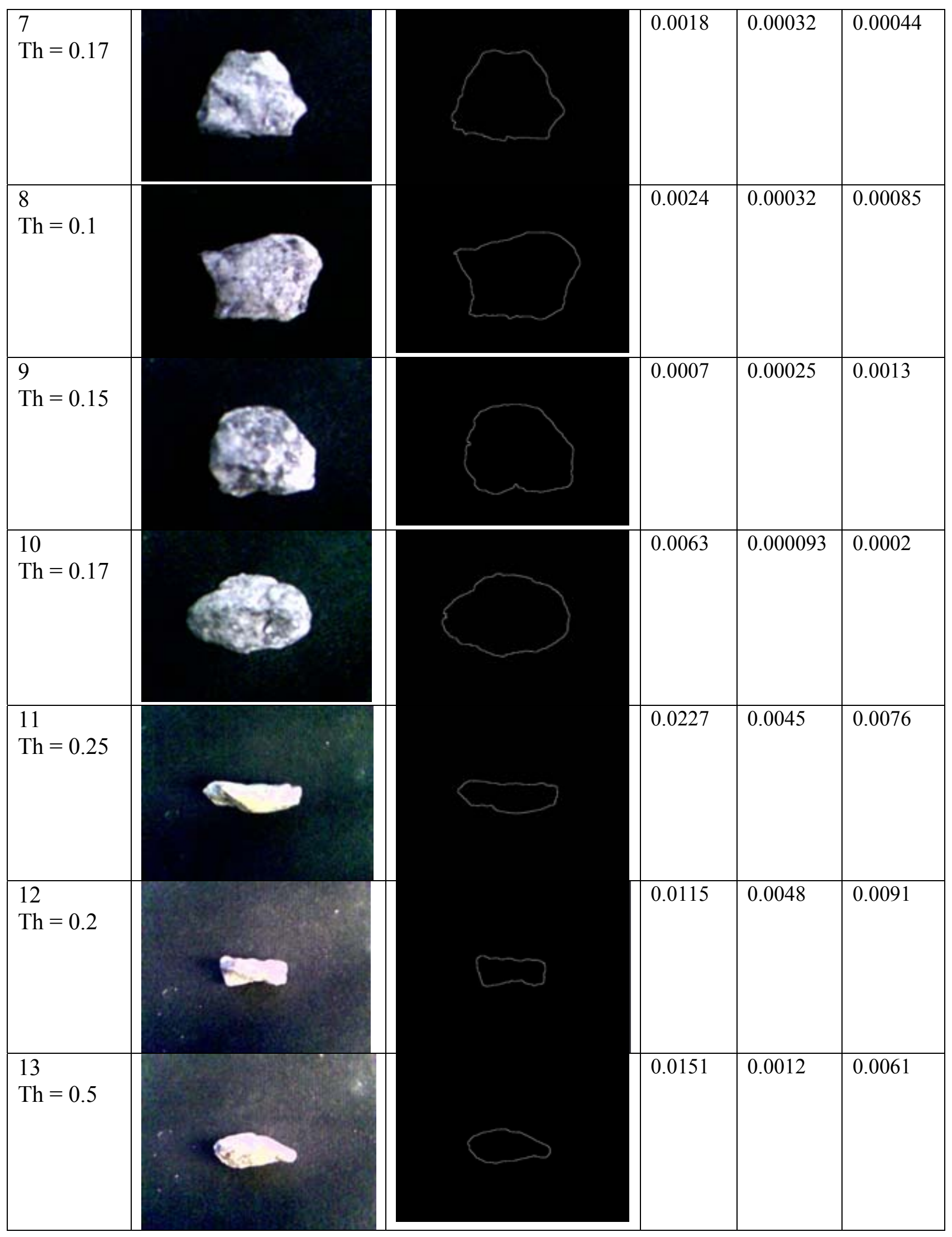




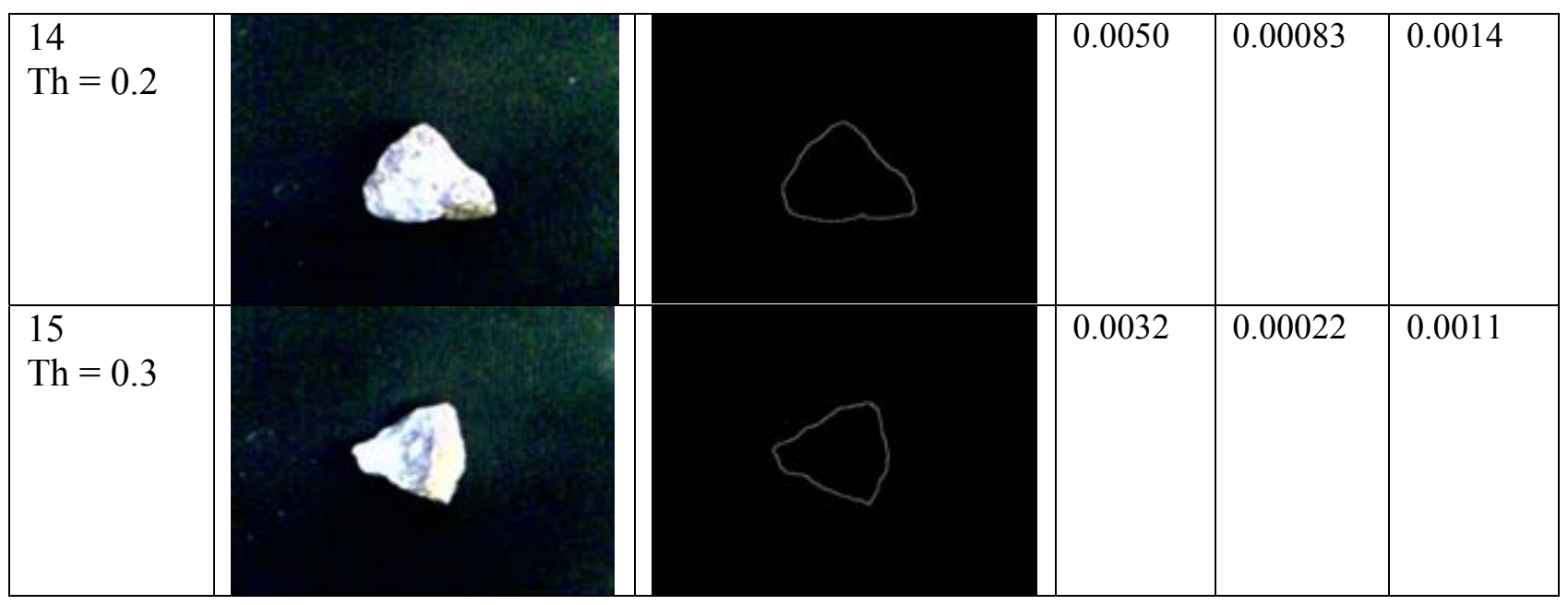




\section{APPENDIX B}

STUDENT T-TEST STATISTICS $(\alpha=0.05)$

\begin{tabular}{|c|c|c|c|}
\hline Aggregate Sets & $\begin{array}{l}\text { Shape } \\
\text { TTest }\end{array}$ & $\begin{array}{l}\text { Angularity } \\
\text { TTest }\end{array}$ & Texture TTest \\
\hline T Test $1-2$ & 0.3565 & 0.5987 & 0.9550 \\
\hline T Test $1-3$ & 0.0836 & 0.7189 & 0.4123 \\
\hline T Test $1-4$ & 0.9552 & 0.7873 & 0.2678 \\
\hline T Test $1-5$ & 0.9764 & 0.2417 & 0.0223 \\
\hline T Test $1-6$ & 0.6321 & 0.2282 & 0.5548 \\
\hline T Test $1-7$ & 0.8537 & 0.5477 & 0.3380 \\
\hline T Test $1-8$ & 0.3384 & 0.1102 & 0.3342 \\
\hline T Test 1-9 & 0.8490 & 0.1512 & 0.5392 \\
\hline $\mathrm{T}$ Test $1-10$ & 0.1567 & 0.6069 & 0.6024 \\
\hline T Test 2-3 & 0.6020 & 0.4587 & 0.4994 \\
\hline T Test 2-4 & 0.5071 & 0.5064 & 0.4515 \\
\hline T Test 2-5 & 0.4058 & 0.1359 & 0.1991 \\
\hline T Test 2-6 & 0.6786 & 0.1468 & 0.6431 \\
\hline T Test 2-7 & 0.5590 & 0.3203 & 0.4879 \\
\hline T Test 2-8 & 0.8752 & 0.0524 & 0.2027 \\
\hline T Test 2-9 & 0.4883 & 0.0778 & 0.5668 \\
\hline $\mathrm{T}$ Test $2-10$ & 0.4518 & 0.3317 & 0.7273 \\
\hline T Test 3-4 & 0.1509 & 0.9454 & 0.9506 \\
\hline T Test 3-5 & 0.2431 & 0.3597 & 0.0567 \\
\hline T Test 3-6 & 0.2684 & 0.2970 & 0.2239 \\
\hline T Test 3-7 & 0.2301 & 0.9437 & 0.9188 \\
\hline T Test 3-8 & 0.6346 & 0.2126 & 0.0633 \\
\hline T Test 3-9 & 0.3210 & 0.1266 & 0.1466 \\
\hline $\mathrm{T}$ Test 3-10 & 0.9247 & 0.8106 & 0.2668 \\
\hline T Test 4-5 & 0.9750 & 0.2417 & 0.0259 \\
\hline T Test 4-6 & 0.7632 & 0.2849 & 0.0443 \\
\hline T Test 4-7 & 0.9457 & 0.8418 & 0.8734 \\
\hline T Test 4-8 & 0.3457 & 0.1257 & 0.0903 \\
\hline T Test 4-9 & 0.9502 & 0.1980 & 0.1964 \\
\hline $\mathrm{T}$ Test $4-10$ & 0.2637 & 0.8027 & 0.2761 \\
\hline T Test 5-6 & 0.7212 & 0.6235 & 0.3274 \\
\hline T Test 5-7 & 0.9162 & 0.3177 & 0.0371 \\
\hline T Test 5-8 & 0.3039 & 0.8049 & 0.8334 \\
\hline T Test 5-9 & 0.9281 & 0.5624 & 0.6174 \\
\hline $\mathrm{T}$ Test $5-10$ & 0.1876 & 0.5382 & 0.2559 \\
\hline
\end{tabular}




\begin{tabular}{|l|l|l|l|}
\hline \hline T Test 6-7 & 0.8159 & 0.2937 & 0.1289 \\
\hline T Test 6-8 & 0.5836 & 0.6652 & 0.5640 \\
\hline T Test 6-9 & 0.8321 & 0.9569 & 0.8013 \\
\hline T Test 6-10 & 0.3281 & 0.2076 & 0.9506 \\
\hline \hline T Test 7-8 & 0.2839 & 0.0614 & 0.0921 \\
\hline T Test 7-9 & 0.9994 & 0.2104 & 0.1688 \\
\hline T Test 7-10 & 0.2701 & 0.8698 & 0.2833 \\
\hline \hline T Test 8-9 & 0.5202 & 0.6263 & 0.7243 \\
\hline T Test 8-10 & 0.6121 & 0.4003 & 0.5538 \\
\hline T Test 9-10 & 0.3033 & 0.1653 & 0.8216 \\
\hline \hline
\end{tabular}




\section{APPENDIX C}

\section{MATLAB 6.5 PROGRAM CODE}

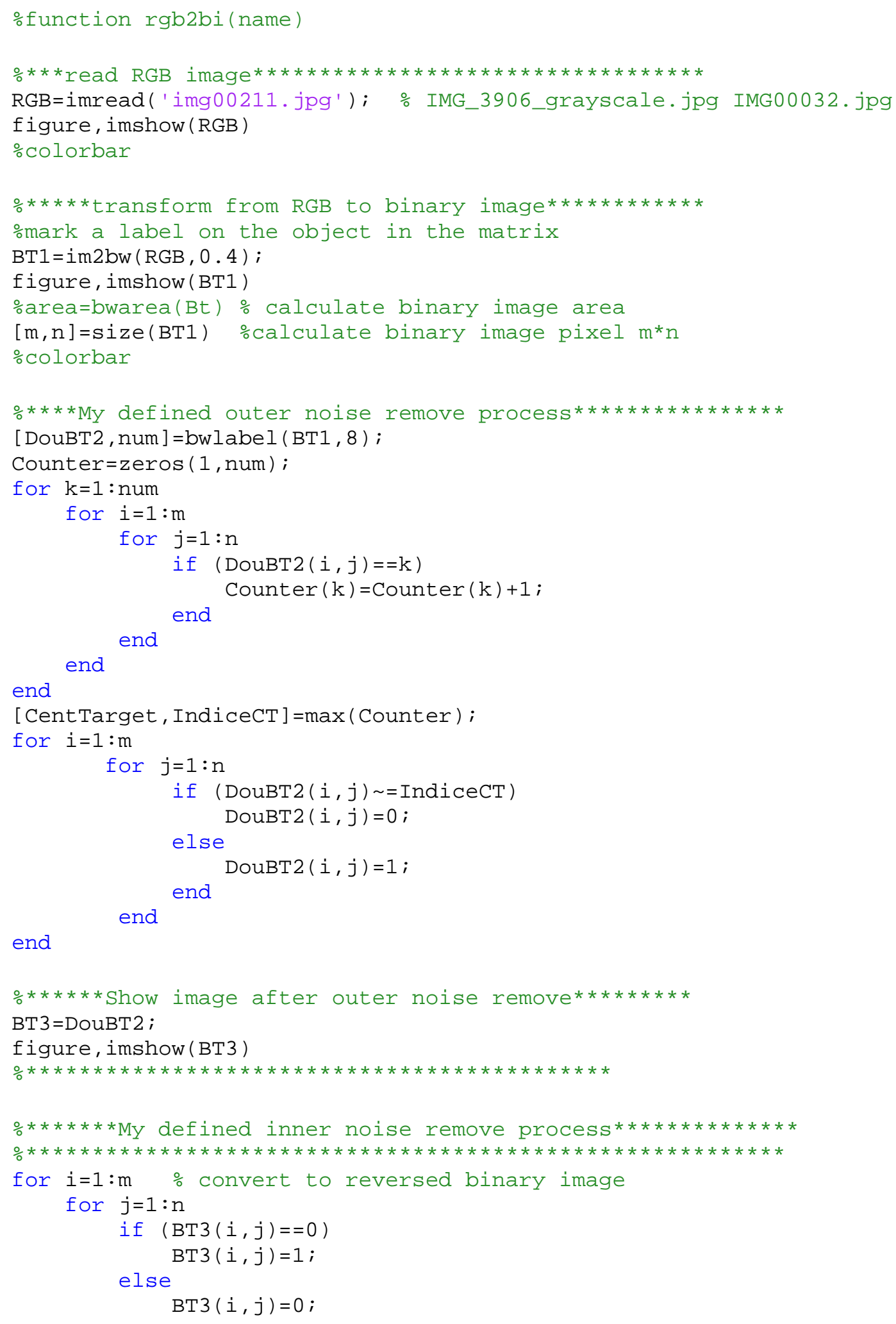




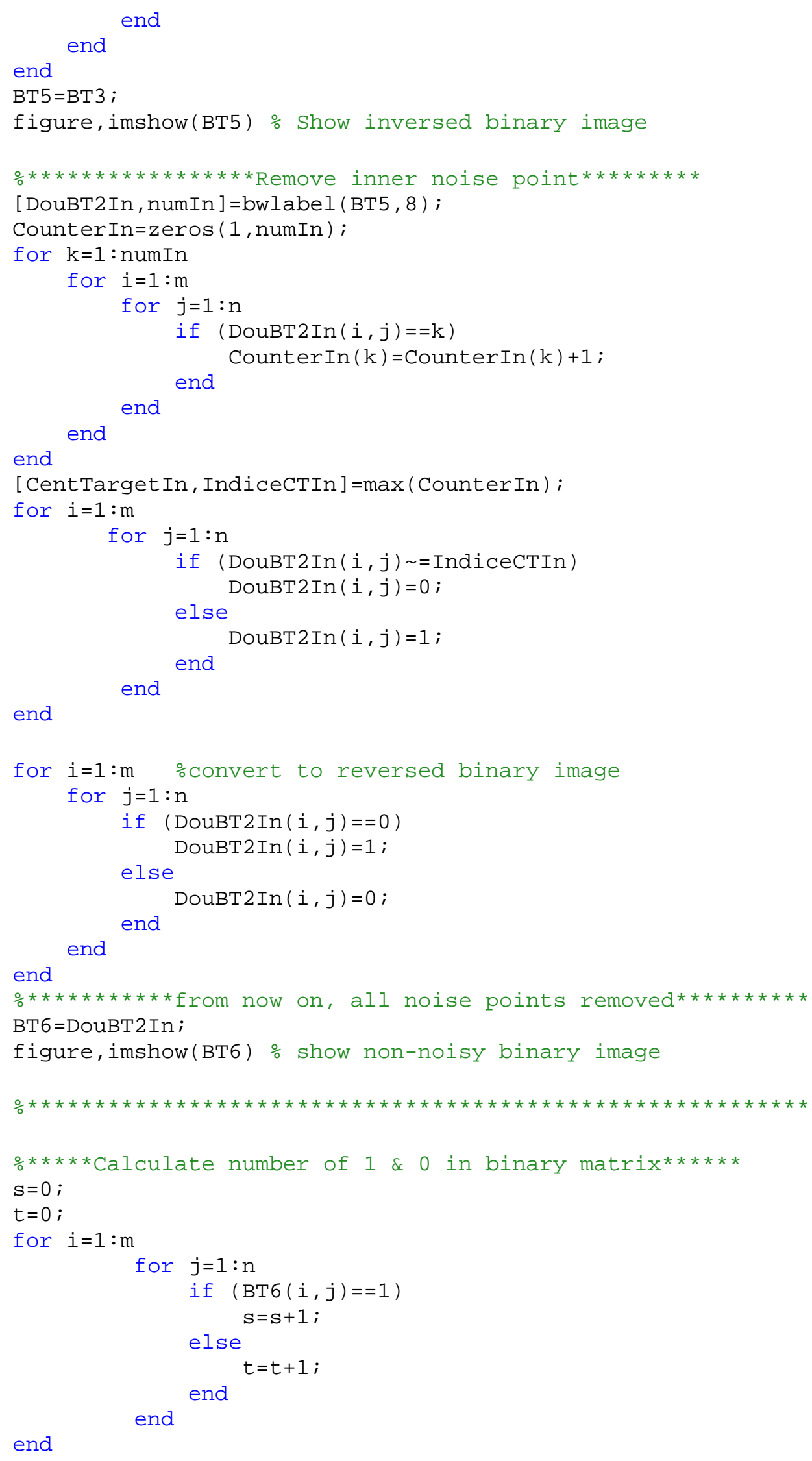




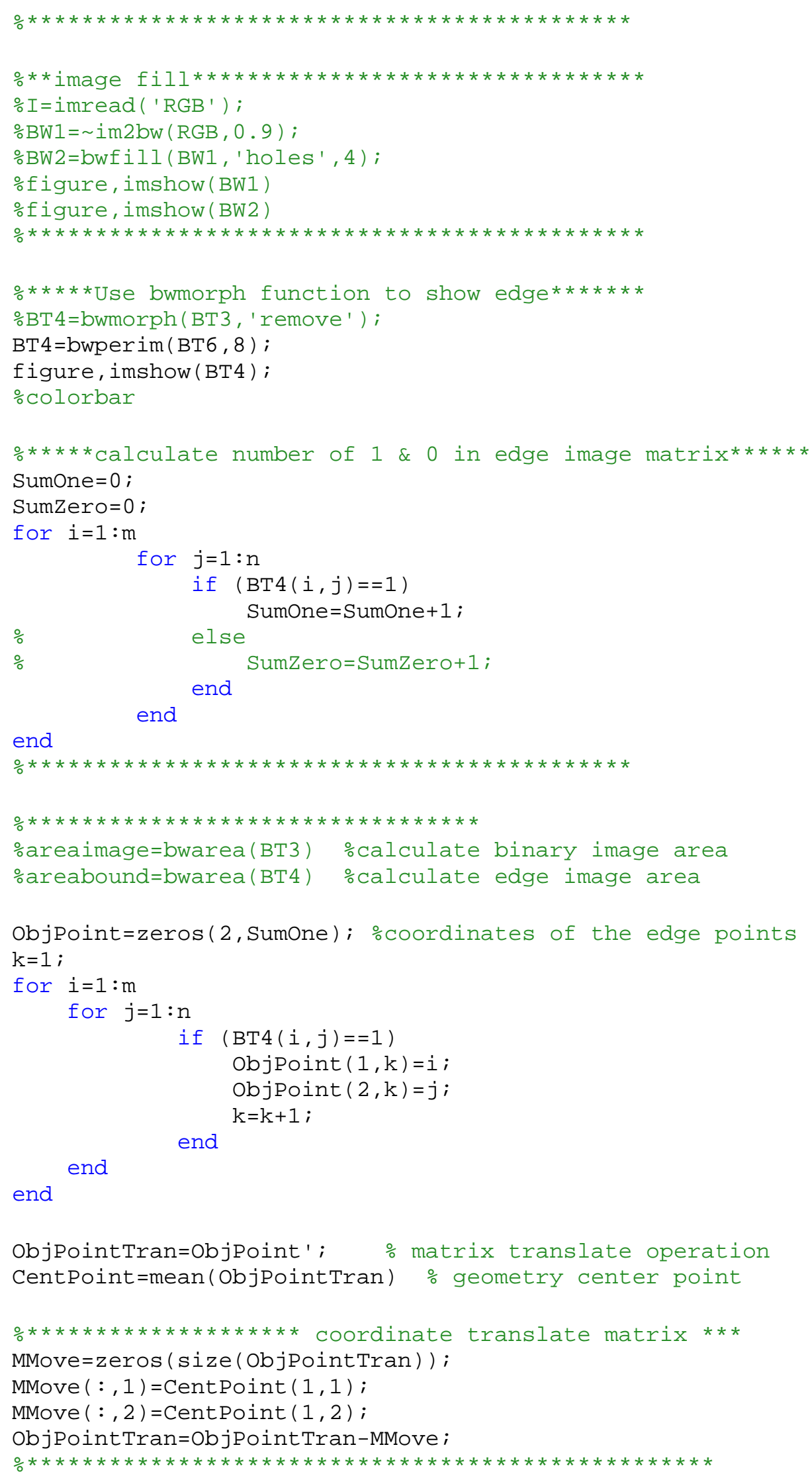




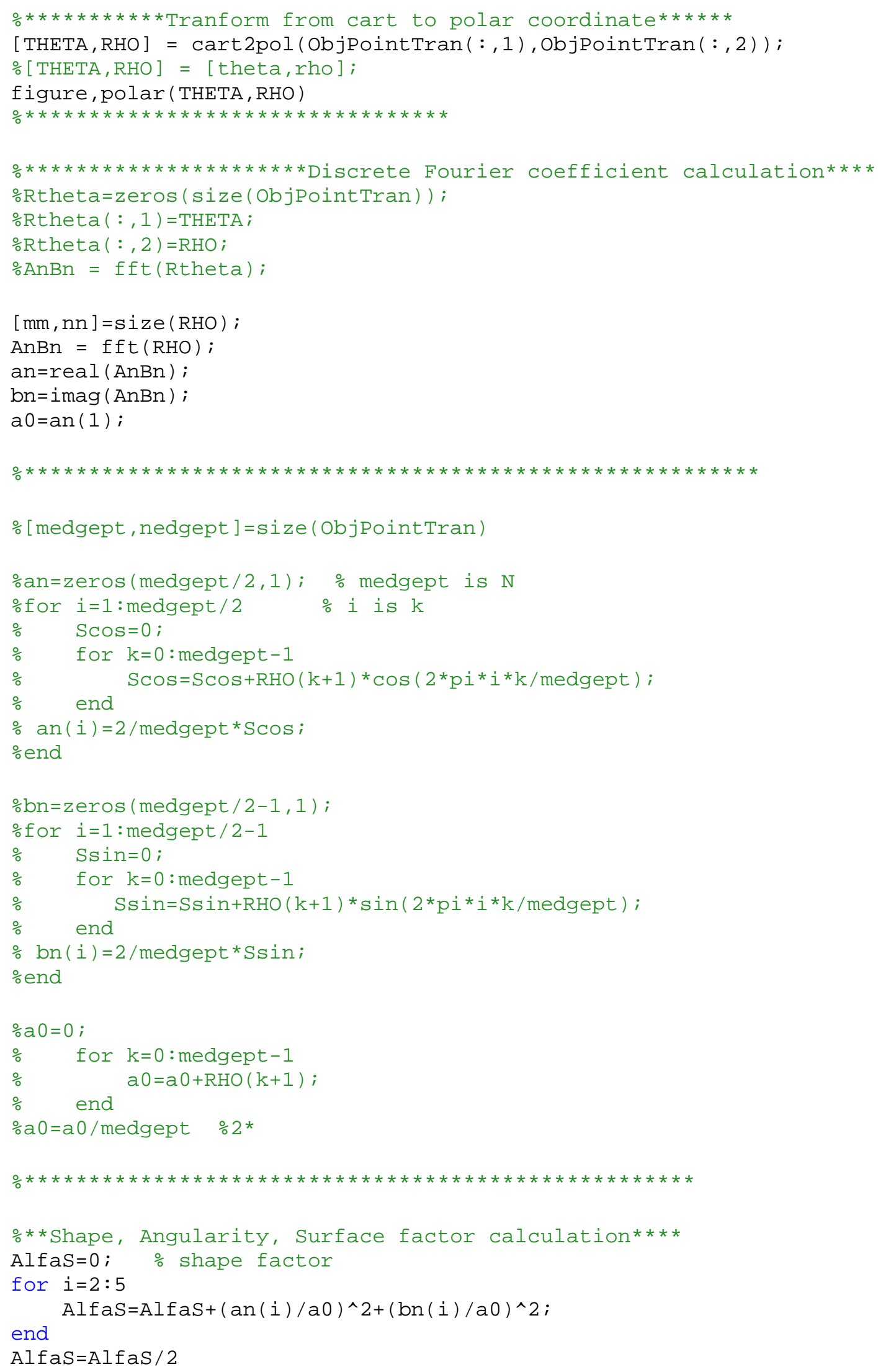




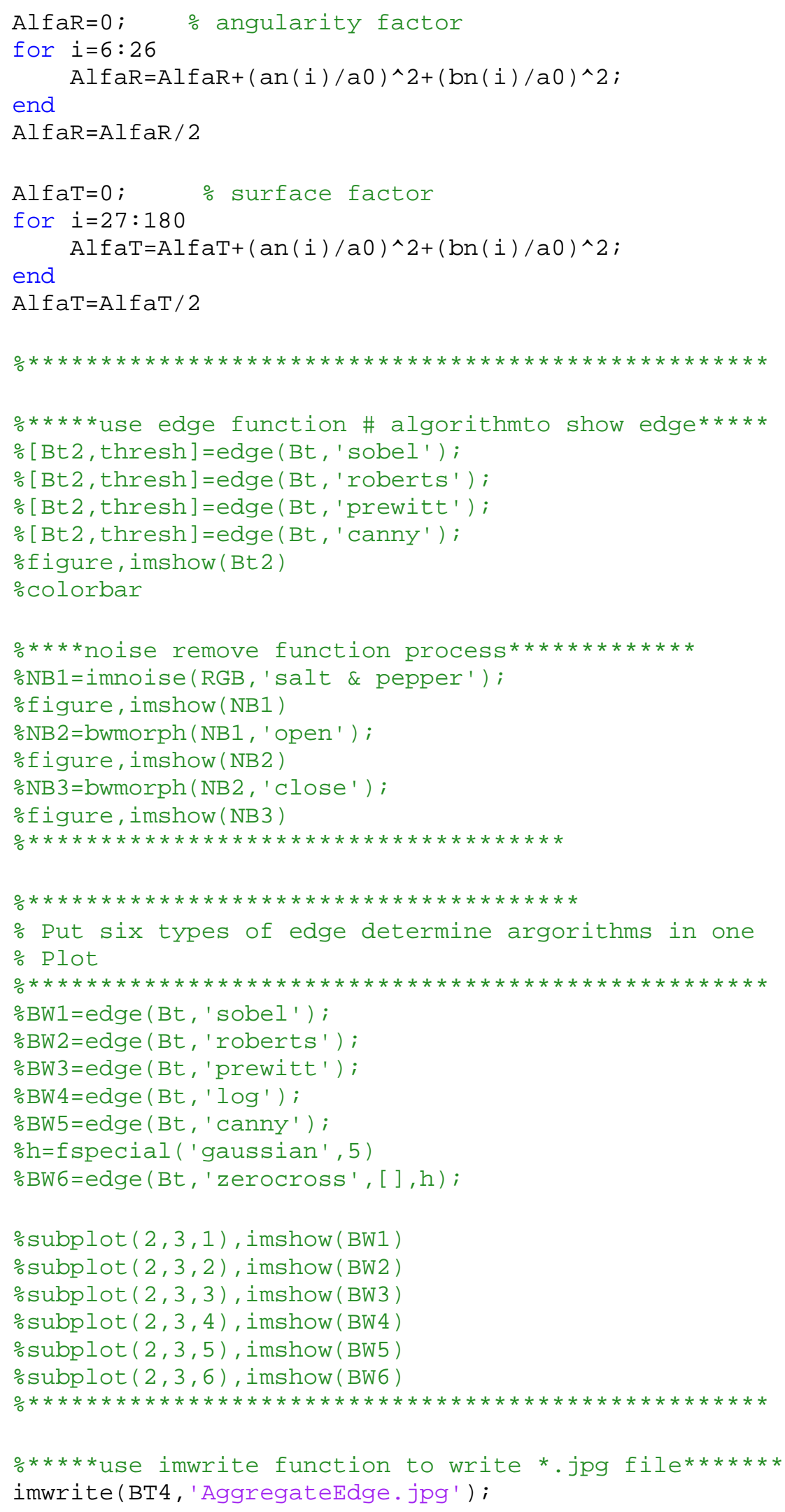

